\title{
Contagion as Domino Effect in Global Stock Markets
}

\author{
Thijs Markwat, Erik Kole, and Dick van Dijk
}

\begin{tabular}{|l|l|}
\hline \multicolumn{2}{|l|}{ ERIM REPORT SERIES RESEARCH IN MANAGEMENT } \\
\hline ERIM Report Series reference number & ERS-2008-071-F\&A \\
\hline Publication & April 2009 \\
\hline Number of pages & 47 \\
\hline Persistent paper URL & http://hdl.handle.net/1765/13835 \\
\hline Email address corresponding author & markwat@ese.eur.nl \\
\hline Address & Erasmus Research Institute of Management (ERIM) \\
& RSM Erasmus University / Erasmus School of Economics \\
& Erasmus Universiteit Rotterdam \\
& P.O.Box 1738 \\
& 3000 DR Rotterdam, The Netherlands \\
& Phone: + 31 10 408 1182 \\
& Fax: $\quad+31104089640$ \\
& Email: info@erim.eur.nl \\
& Internet: $\quad$ www.erim.eur.nl \\
\hline
\end{tabular}

Bibliographic data and classifications of all the ERIM reports are also available on the ERIM website: www.erim.eur.nl 


\section{ERASMUS RESEARCH INSTITUTE OF MANAGEMENT}

\section{REPORT SERIES}

\section{RESEARCH IN MANAGEMENT}

\begin{tabular}{|l|l|}
\hline \multicolumn{2}{|l|}{ ABSTRACT AND KEYWORDS } \\
\hline Abstract & $\begin{array}{l}\text { This paper shows that stock market contagion operates through a domino effect, where confined } \\
\text { local crashes evolve into more widespread crashes. Using a novel framework based on ordered } \\
\text { logit regressions we model the occurrence of local, regional and global crashes as a function of } \\
\text { their past occurrences crashes and financial variables. We find significant evidence that global } \\
\text { crashes do not occur abruptly but are preceded by local and regional crashes. Besides this form } \\
\text { of contagion, interdependence shows up by the effect of interest rates, bond returns and stock } \\
\text { market on crash probabilities. When it comes to forecasting global crashes, our model } \\
\text { outperforms a binomial model for global crashes only. }\end{array}$ \\
\hline Free Keywords & contagion, stock market crises, interdependence \\
\hline Availability & $\begin{array}{l}\text { The ERIM Report Series is distributed through the following platforms: } \\
\text { Academic Repository at Erasmus University (DEAR), DEAR ERIM Series Portal } \\
\text { Social Science Research Network (SSRN), SSRN ERIM Series Webpage } \\
\text { Research Papers in Economics (REPEC), REPEC ERIM Series Webpage }\end{array}$ \\
\hline Classifications & $\begin{array}{l}\text { The electronic versions of the papers in the ERIM report Series contain bibliographic metadata } \\
\text { by the following classification systems: } \\
\text { Library of Congress Classification, (LCC) LCC Webpage } \\
\text { Journal of Economic Literature, (JEL), JEL Webpage } \\
\text { ACM Computing Classification System CCS Webpage } \\
\text { Inspec Classification scheme (ICS), ICS Webpage }\end{array}$ \\
\hline
\end{tabular}




\title{
Contagion as Domino Effect in Global Stock Markets*
}

\author{
Thijs Markwat ${ }^{\dagger} \quad$ Erik Kole \\ Dick van Dijk \\ Econometric Institute, Erasmus University Rotterdam
}

April 3, 2009

\begin{abstract}
This paper shows that stock market contagion operates through a domino effect, where confined local crashes evolve into more widespread crashes. Using a novel framework based on ordered logit regressions we model the occurrence of local, regional and global crashes as a function of their past occurrences crashes and financial variables. We find significant evidence that global crashes do not occur abruptly but are preceded by local and regional crashes. Besides this form of contagion, interdependence shows up by the effect of interest rates, bond returns and stock market on crash probabilities. When it comes to forecasting global crashes, our model outperforms a binomial model for global crashes only.
\end{abstract}

Keywords: Contagion, Stock market crises, Interdependence JEL classification: C35, F37, G10, G15

${ }^{*}$ We would like to thank Mardi Dungey, Leora Klapper, Stefanie Kleimeier and Mathijs van Dijk, as well as participants at the 2008 World Bank - IMF Conference on Risk Analysis and Management and the 6th Paris finance international meeting for helpful comments and suggestions.

$\dagger$ Corresponding author: Erasmus University Rotterdam, P.O. Box 1738, NL-3000 DR Rotterdam, The Netherlands. E-mail addresses markwat@few.eur.nl, kole@few.eur.nl, djvandijk@few.eur.nl 


\section{Introduction}

Stock market crashes are one of the major risks that investors face. Although such crashes occur infrequently, their impact on the value of asset portfolios can be substantial. The October 1987 crash, for example, made stock prices decline by over 20 percent in most developed markets. In emerging stock markets, crashes can be even more severe. Asian markets lost over 30 percent in October 1997 during the Asian crisis. As emerging countries are commonly quite susceptible to macroeconomic shocks, crashes occur more often in their stock markets. While many of these crashes are "local" and remain confined to individual countries, some spread to neighboring emerging markets, resulting in regional stock market crashes. Some may even evolve into global crashes, where developed markets are also affected. The 1997 Asian crisis, for instance, originated in Thailand, then infected other developing Asian countries, and finally financial markets in the United States and Western Europe were affected as well.

For investors as well as policy makers it is important to know whether crashes remain local, or a "domino pattern" occurs, with local crashes evolving via regional crashes into global crashes. If crashes remain local, investors could hedge relatively easy. However, hedging is more difficult, and diversification opportunities diminish rapidly, when local crashes spread regionally or even globally. In this case, the domino effect may destabilize several markets and even the entire financial system, calling regulators into action. On the other hand, if markets tumble like domino tiles, a local or regional crash can be interpreted as an early warning signal of more turmoil to follow.

This study empirically examines the transmission mechanism of stock market crashes around the globe, using daily data for the US, Europe and several emerging markets in Latin America and Asia for the period from July 1996 to July 2007. In particular, we investigate whether the evolution of crashes exhibits a domino effect. We first identify periods with local, regional and global crashes (and periods without any crash at all). We then use an ordered logit model for the probabilities of occurrence of the different crash types. An ordered logit model is precisely able to capture the natural ordering of crashes by severity. This setup enables the inclusion of both domino-style contagion and normal interdependence between financial markets. A domino effect is present when past occurrences of local, regional or global crashes significantly increase the probability of more severe crashes. We capture interdependence by including variables that represent information from the currency market, the bond market, and short-term interest rates.

As our main result we find strong evidence in favor of a domino effect. A crash occurring 
today significantly increases the probability of a more severe crash tomorrow. This result holds for all different types of crashes. The domino pattern indicates that global crashes, which can hardly be diversified, do not occur abruptly but rather evolve out of prior local or regional crashes. Our results confirm that in times of financial distress panic indeed spreads contagiously, as described in Dornbusch et al. (2000). A local crash is good predictor of more financial turmoil ahead. Additionally, we find that bond markets returns, interest rate levels and stock market volatility significantly influence local, regional and global crash probabilities, though currency changes do not. Higher interest rates and higher stock market volatility lead to higher probabilities of more severe crashes, while higher bond returns in emerging markets lead to lower crash probabilities. We do not find that the relation between the financial variables and crash likelihood depends on the type of crash that occurred the day before. Finally, we find that our model, allowing for different types of crashes including local and regional ones, is more successful in detecting and forecasting global crashes than a binomial model for global stock market crashes only.

We contribute to the literature in various ways. First, our explicit distinction between local, regional and global crashes, and our model of the evolution of these crashes as a domino effect sheds new light on the propagation of large negative stock market returns. This adds to the approach of Bae et al. (2003) and (to a lesser extent) Cumperayot et al. (2006). Bae et al. (2003) use the number of simultaneous extreme returns in different stock markets as dependent variable in a multinomial logistic regression model and find significant effects of interest rates, changes in currencies and conditional stock market volatility. However, they analyze only one region at a time, and do not investigate which part of the dependence between crashes in different countries can be attributed to reactions on shocks in other financial markets and which part to shocks in other financial variables. We extend their study by explicitly including global crashes in our analysis. These global crashes are most important for investors and regulators, because diversification opportunities evaporate in this case.

Second, we add to the ongoing debate on contagion and interdependence, as discussed in Dornbusch et al. (2000) (see also Pericoli and Sbracia, 2003), by using a framework in which we allow for both types of transmission mechanisms. Interdependence means spillovers of shocks resulting from the normal dependence between markets, due to trade links and geographical position, among others. So, interdependence refers to the dependence that exists in all states of the world. Contagion, on the other hand, constitutes a form of dependence that does not exist in tranquil periods but only occurs for large or extreme 
shocks to financial markets. Contrary to interdependence, this dependence cannot be linked to observed changes in macroeconomic or financial variables. Dornbusch et al. (2000) argue that this type of dependence is a result of "irrational" phenomena, such as financial panic, herd behavior and loss of confidence. We define contagion as the dependence that still exists after correcting for interdependence. Contrary to the common approach, our logistic framework does not measure contagion as correlation between residuals, but instead we construct contagion variables based on past extreme events. This enables us to distinguish between contagion and interdependence in the occurrence and evolution of local, regional and global crashes.

Most other studies concerning interdependence and contagion are based on bivariate analyses, and do not investigate dependence at the global level. The most popular approach is based on correlations between returns in different markets. ${ }^{1}$ Kleimeier et al. (2008) show that these correlation based tests may lead to wrong conclusions due to different trading hours. Using time-aligned data they find contagion during the Asian crisis, contrary to Forbes and Rigobon (2002). Other authors attempt to model the volatility transmission mechanism by means of multivariate GARCH models ${ }^{2}$ or use extreme value theory ${ }^{3}$ to avoid the problem that increased correlations in periods of turmoil may be mostly a result of increased volatility. ${ }^{4}$ Rodriquez (2007) uses copulas to measure contagion and finds evidence for contagion based on changes in dependence of extreme returns. Other studies making the distinction between interdependence and contagion are Connolly and Wang (2003) and Fazio (2007), where the latter concludes that interdependence exists between regions and contagion only within regions, and the former reject interdependence between regions while finding contagion between regions. Recently, Boyer et al. (2006) investigate the spread of crises through asset holdings of international investors, and find that this is an additional channel through which crises can spread. Our research is complementary to these studies.

A small number of previous studies consider crises and contagion in a multicountry environment. For instance, Dungey and Martin (2007) use factor models with world, regional and country factors and define contagion as the correlation between the residuals. This approach, however, is not specifically suited for measuring dependence among extreme shocks. The logistic approach, as pointed out by Bae et al. (2003), is more suitable to

\footnotetext{
${ }^{1}$ See King and Wadhwani (1990); Lee and Kim (1993); Loretan and English (2000) and Forbes and Rigobon (2002).

${ }^{2}$ See Hamao et al. (1990), Longin and Solnik (1995), and Ng (2000).

${ }^{3}$ See Kaminsky and Schmukler (1999), Longin and Solnik (2001), and Hartmann et al. (2004).

${ }^{4}$ See Boyer et al. (1999), Loretan and English (2000), Forbes and Rigobon (2002).
} 
deal with extreme values, for the reason that it is closely related with extreme value theory. Christiansen and Ranaldo (2009) apply the methodology of Bae et al. (2003) to the stock markets of the EU and its new members and find evidence of a increased dependence of new EU stock markets to those in Western Europe. Other studies that use a multicountry environment are Favero and Giavazzi (2002) on exchange rate contagion, and Kose et al. (1990) who use a Bayesian framework to model output, consumption and investment. However, these two approaches are also not specifically suited for analyzing crashes. Kamin (1999) and more recently Dungey et al. (2008) empirically analyze whether the role of economic fundamentals (linkages) and contagion varies across financial crises. Although some differences are found, generally all crises seem to have much in common. For a comprehensive overview on recent developments in the contagion literature we refer to Dungey et al. (2005).

The paper proceeds as follows. In Section 2 we describe the data set, and provide our definition of a stock market crash as well as the classification into local, regional and global crashes. In Section 3 we put forth the methodology for analyzing the domino effect based on the ordered logit model. In Section 4 we discuss the empirical results concerning the patterns in the different types of crashes, including several sensitivity tests. Section 5 explores the economic relevance of our model compared to a binomial crash model for global crashes only. We conclude in Section 6.

\section{The dynamics of stock market crashes}

In this section we first discuss our data and definitions of local, regional and global stock market crashes. We then document the dynamic properties of the different crash types, to examine the appropriateness of modelling contagion as a domino effect.

\section{$2.1 \quad$ Data}

We investigate the transmission of stock market crashes for emerging markets in Latin America and Asia, and developed markets in the US and Europe. We include six countries from Latin America: Argentina, Brazil, Chile, Colombia, Mexico and Venezuela, as well as six countries from Asia: India, Korea, Malaysia, Philippines, Taiwan and Thailand. We obtain country and regional indices from the IFC emerging market database (EMDB), currently maintained by Standard \& Poors. For the US and Europe we use MSCI equity indices. Although Europe exist of more countries rather than one, we do not consider local 
crashes in Europe for two reasons. First, the stocks markets in Western Europe are highly integrated. Second, regarding Europe as a region leads to a symmetric treatment of the US and Europe. We base our analysis on daily returns in US dollars for the period from July 1, 1996 until July 30, 2007, giving a total of 2839 observations. All the data are taken from Datastream.

\section{[Insert Table 1 around here]}

Table 1 provides summary statistics of the log daily stock returns for the full sample period. The regional indices show that emerging markets are riskier than developed markets, while the average returns are perhaps not as high as might be expected to compensate for this higher risk. This can be explained by the 1997 Asian crisis and the 1998 Russian debt crisis, which considerably depressed emerging market returns. ${ }^{5}$ Within the emerging market countries the annualized average returns vary widely, ranging from a minimum of $-7 \%$ in Thailand to a maximum of $16 \%$ in Mexico. The volatilities also show large variation across countries. For example, the Chilean stock market has a volatility of only $17 \%$ per year, while volatility in Korea is much higher and equal to $42 \%$. Volatility generally exceeds $25 \%$, indicating the high investment risk typical for emerging markets. Kurtosis is also substantially higher than for the developed markets, pointing out that extremely large returns occur more often in emerging markets. Interestingly, skewness is negative for the Latin American countries, while it is positive for the Asian markets (except India). The biggest crash in the sample was observed on 29 November 2002, when the Venezuelan index lost $46 \%$ of its value. Maximum returns also vary from moderate (Chile, India, Taiwan) to very high (Venezuela, Korea, Malaysia, Philippines).

The last three rows of the upper part of Table 1 report the 5th quantile of the empirical return distribution together with the mean and volatility of returns in the left tail below this quantile. The extreme returns have the lowest mean and highest volatility for Argentina, Korea and Venezuela, indicating that in these countries the extreme returns introduce more risk and vary more than in the other countries. For the regional indices, we observe that the 5th quantile, and the mean and volatility of returns in the left tail are approximately equal for Asia, US and Europe, while they are substantially larger (in absolute value) for Latin America. From this perspective Latin America would be the most risky region to invest in.

\footnotetext{
${ }^{5}$ Average yearly returns computed over the period $1999-2007$ are equal to $21,13,2$ and $5 \%$ for Latin America, Asia, the US and Europe, respectively, which are more in line with their respective volatilities.
} 
The entries below the main diagonal in the bottom part of Table 1 are linear correlation coefficients between contemporaneous daily returns. For the regional indices, we observe that the correlations between the US, Europe and Latin America are of the same order of magnitude around 0.50. The correlations between Asia and the other regions are lower, especially the correlation between the US and Asia (0.09). This lower correlation is mainly a result of different trading hours of stock markets around the globe. As trading on a given calendar day starts in Asia, then moves to Europe, and ends in the US, information from the European and (especially) the US stock markets cannot affect the Asian market on the same day, such that these correlations (mostly) measure the effect of the Asian market on Europe and the US. The correlations between current returns in Asia and one-day lagged returns in Europe and the US (0.29 and 0.38, respectively), are more in line with the other regional correlations.

The correlations between individual emerging markets are somewhat lower on average. The average correlations between countries within Latin America and Asia are equal to 0.29 and 0.24 , respectively, while the average cross-correlation (the correlation between the countries in Asia and Latin America) is only 0.12. We note, though, that the correlations between the four largest Latin American markets (Argentina, Brazil, Chile and Mexico) are considerably higher at around 0.50, comparable to the correlation among developed markets.

\subsection{Crash definition and classification}

Following Bae et al. (2003), a stock market crash in a given country occurs when the daily return lies below the 5th quantile of the empirical return distribution over the complete sample period. A local crash occurs when one to three individual emerging markets experience a crash, while the respective regional indices do not. ${ }^{6}$ A regional crash in Latin America, Asia, the US or Europe occurs when the respective regional index has a daily return below the 5th quantile of the empirical return distribution. In addition, for Latin America and Asia a regional crash occurs when four or more country indices in the region experience a crash. This additional definition enables us to observe a regional crash in the emerging markets when only small countries crash. Otherwise, results could be driven by large countries such as Brazil, Mexico, Korea and Thailand, as the IFC indices are valueweighted. We define a global crash as the simultaneous occurrence of two or more regional crashes, of which at least one is in a developed region. Because of the differences in stock

\footnotetext{
${ }^{6}$ Results hardly change when we vary this number between three to six markets.
} 
market trading hours, we also define a global crash when the US or Europe encounters a crash on day $t$, followed by a crash in Asia on day $t+1 .^{7}$ As stock markets rapidly, possibly instantaneously, adjust to shocks (Kleimeier et al., 2008), we use the highest possible sampling frequency available, which is daily. ${ }^{8}$

Based on the definitions given above, no crash occurs on 1810 days, out of a total of 2839 days in the full sample period. Local, regional, and global crashes occur on 616, 271, and 142 days, respectively. Hence, regional crashes occur slightly more often than once every two weeks and global crashes about once a month. Although this may seem quite frequent, it should be noted that crashes are clustered. Typically, several global crashes occur in short time-periods, alternated by long periods with hardly any global crashes. To examine whether these numbers are high or low we compute the expected numbers of crashes assuming all markets are independent. Since the crash probability equals $5 \%$ for all indices by construction, these can be computed analytically. This results in an expected number of 1228 days without any type of crash, and 1066, 497, 48 days with a local, regional and global crash, respectively. Comparing these numbers to the actual numbers of crashes shows that the crash risk involved with investing in equity markets is indeed rather large. Although the numbers of days with a local or regional crash in our sample are lower than expected under independence, global stock market crashes, which are the most troublesome for investors, occur three times more often.

The entries above the main diagonal in the lower part of Table 1 are conditional probabilities of observing a crash in a specific stock market, given the occurrence of a crash in another market. These probabilities give insight into the dependence of extreme stock market returns. By construction, the same number of crashes occur for all individual markets, and therefore these probabilities are also symmetric. For the regional indices we find that the probability of observing a crash given that another region encounters a crash is around 0.30 on average. For the individual markets in both Latin America and Asia we find substantial variation in these conditional probabilities, although most are between 0.10 and 0.20 . To put these numbers into perspective, note that if all markets were independent these conditional probabilities would be equal to 0.05 . Hence, the empirical conditional probabilities show that there is substantial dependence in the occurrence of crashes across countries and regions.

\footnotetext{
${ }^{7}$ We note that differences in trading hours are crucially important when analyzing relations between daily stock market returns, see Kleimeier et al. (2008), but to a much lesser extent when counting extreme events, as we do here.

${ }^{8}$ We also perform our analysis with 2-day returns, which gives qualitatively similar results. Details are available upon request.
} 


\subsection{Crash dynamics}

We continue by documenting some stylized facts on the dynamic properties of the different types of crashes. Specifically, we introduce a diagnostic measure which sheds light on how local, regional and global crashes evolve. This measure, which we call the crash transition matrix, is useful in particular to assess whether modelling contagion as a domino effect is appropriate. The $i j$-th entry of this transition matrix is equal to the probability of observing the state in column $j$, given that on the previous day the state in row $i$ occurred. The states correspond with the different types of crashes.

\section{[Insert Table 2 around here]}

Table 2A shows the empirical crash transition matrix. Several interesting observations emerge. First, the probabilities of observing a crash (no matter what type) tomorrow increases from 0.28 when no crash occurs today via 0.43 and 0.55 to 0.73 when a global crash occurs today. For both regional and global crashes we find increasing probabilities of occurrence, conditional on the occurrence of a crash on the previous day. The probabilities of observing a global crash, for example, increase from 0.03 when no crash occurred on the previous day, via 0.06 to 0.11 following the occurrence of a local or regional crash, respectively. Most global crashes do not occur abruptly but rather evolve out of prior local or regional crashes, which suggests that modelling contagion as a domino effect makes sense. Second, crashes of a given type are persistent. The probability that a certain crash continues is much higher than the probability of occurrence of the same type of crash on two consecutive days if these were independent. For example, the empirical probability that a global crash continues is $20 \%$, which is more than 80 times as large as the probability of $\left(\frac{142}{2839}\right)^{2}=0.25 \%$ of observing two consecutive days with a global crash if these occurrences were independent. The same holds for local and regional crashes. Third, crashes die out gradually as indicated by the relatively high probabilities that a regional crash occurs tomorrow following a global one today, or a local crash following a regional one.

Boyer et al. (1999), Loretan and English (2000), and Forbes and Rigobon (2002) argue that increased correlations between stock market returns in times of extreme downturns can be attributed to increased volatility during these periods. To examine whether our results for the crash dynamics are driven by this volatility effect, we compute the crash transition matrix using crash definitions based on standardized returns. ${ }^{9}$ Table $2 \mathrm{~B}$ shows

\footnotetext{
${ }^{9}$ We use the sample volatility over the past year to standardize the returns. For the standardized
} 
that the transition probabilities are approximately equal to those found for the crashes based on raw returns. We conclude that the dynamic dependence between crashes is not affected by time-varying levels of volatility.

Finally, we examine whether the crash dynamics are mainly driven by linear autocorrelation or higher-order or non-linear effects are at work. For this purpose we employ the stationary bootstrap of Politis and Romano (1994). Contrary to the standard i.i.d. bootstrap, this bootstrap method can take autocorrelation into account. Instead of drawing subsequent observations in the bootstrap sample completely at random, they are drawn in the natural ordering with a specific probability $(p)$. The optimal value of $p$ can be determined using the method of Politis and White (2004). ${ }^{10}$ For our data this turns out to be $p=0.50 .{ }^{11}$ Using the stationary bootstrap, we obtain a bootstrapped sample of 2839 observations, corresponding with the length of the empirical return series, and compute its crash transition matrix. If the transmission mechanism of crashes is mainly driven by linear autocorrelation, the bootstrapped matrix should be approximately equal to the empirical crash transition matrix.

Table 2C shows the average transition matrix based on 10,000 bootstrapped samples. Again we observe higher probabilities for regional and global crashes when a crash occurred on the previous day. However, the pattern is less clear than for the original data. For the transitions between regional and global crashes the differences between the original and the bootstrapped crash transition matrix become particularly large. For instance, the probability of observing a regional crash today and a global crash tomorrow decreases from 0.11 to 0.07 . The probability that a global crash continues is 0.11 , much less than the 0.20 in panel $\mathrm{A}$. This indicates that there are indeed higher-order dependencies in the dynamic patterns of crashes, especially concerning the more severe crashes. Again, using standardized returns has hardly any influence on the results (see Table 2D).

\section{Methodological framework}

The increasing probabilities of occurrence of regional and global crashes following a crash on the previous day clearly indicate that stock market crashes gradually disseminate and

returns, we find 1801, 621, 289 and 128 days with no, local, regional and global crash, respectively.

${ }^{10}$ This method minimizes the mean squared errors of the variances and autocovariances of the stationary bootstrapped data, given that the first draw is random.

${ }^{11}$ We computed the optimal values of $p$ for the four regional indices and then took the average. The individual values of $p$ for the sample returns are $0.73,0.83,0$ and 0.42 , for Latin America, Asia, USA and Europe respectively. For the standardized returns these are 0.71, 0.82, 0 and 0.46 . 
evolve into more severe crashes. However, it remains to be seen whether this is due to domino-style contagion or due to normal interdependence between financial markets. We analyze this formally by modelling the evolution of local, regional and global crashes by an ordered logit model. The type of crash at time $t$ can be seen as the outcome of a discrete choice process, and given that the different crash types have a natural ordering by severity, the ordered logit model is appropriate for our modelling purposes.

We denote the observed crash on day $t$ as $y_{t}$, taking the values $0,1,2$ or 3 when no crash, or a local, regional or global crash occurs, respectively. The observation $y_{t}$ is assumed to be related with the latent continuous variable $y_{t}^{*}$ by

$$
y_{t}=j \quad \text { if } \alpha_{j}<y_{t}^{*}<\alpha_{j+1}, \quad \text { for } j=0 \ldots m-1
$$

where in our case $m=4$. The $\alpha_{j}$ for $j=0, \ldots, m$ are thresholds separating the different crash categories, where $\alpha_{0} \equiv-\infty$ and $\alpha_{m} \equiv \infty$. In the ordered logit model the latent variable $y_{t}^{*}$ is linearly related to a vector of covariates $\boldsymbol{x}_{t}$, that is $y_{t}^{*}=\boldsymbol{x}_{t}^{\prime} \boldsymbol{\beta}+\varepsilon_{t}$, with $\varepsilon_{t}$ assumed to follow a standardized logistic distribution. The choice of variables entering $\boldsymbol{x}_{t}$, discussed below, will enable us to distinguish between a domino contagion effect and interdependence as the underlying cause for the propagation of stock market crashes. Using the link between $y_{t}$ and $y_{t}^{*}$ as specified above, the probability of observing a crash of type $j$ at time $t$ is given by:

$$
p_{j t}=P\left[y_{t}=j\right]=\Lambda\left(\alpha_{j+1}-\boldsymbol{x}_{t}^{\prime} \boldsymbol{\beta}\right)-\Lambda\left(\alpha_{j}-\boldsymbol{x}_{t}^{\prime} \boldsymbol{\beta}\right), \quad \text { for } j=0, \ldots, m-1
$$

where $\Lambda$ is a logistic function, and $\Lambda\left(\alpha_{0}-\boldsymbol{x}_{t}^{\prime} \boldsymbol{\beta}\right) \equiv 0$ and $\Lambda\left(\alpha_{m}-\boldsymbol{x}_{t}^{\prime} \boldsymbol{\beta}\right) \equiv 1$.

The coefficients $\boldsymbol{\beta}$ and the thresholds $\alpha_{j}, j=1, \ldots, m-1$, in the ordered logit model can be estimated straightforwardly by maximum likelihood, where the log likelihood for a sample of $T$ observations is given by

$$
\ell\left(\boldsymbol{\beta}, \alpha_{1}, \alpha_{2}, \alpha_{3}\right)=\sum_{t=1}^{T} \sum_{j=0}^{m-1} I\left[y_{t}=j\right] \log \left(p_{j t}\right)
$$

where $I\left[y_{t}=j\right]=1$ if observation $t$ was of type $j$ and zero otherwise. We use White misspecification robust standard errors. In line with other studies using models with limited dependent variables, we use the pseudo- $R^{2}$ of McFadden (1974) as a measure of fit of the model. If the loglikelihood of the full, unrestricted model is denoted by $\ell_{1}$ and the $\log$ likelihood of a restricted model which only includes the threshold parameters by $\ell_{0}$, the 
pseudo- $R^{2}$ is given by

$$
R^{2}=1-\frac{\ell_{1}}{\ell_{0}}
$$

We perform likelihood ratio tests on the individual and joint significance of the coefficients in our model.

Though the coefficient estimates in ordered logit regressions can be interpreted based on their significance and signs, they cannot be used to assess the marginal effects of the covariates on the crash probabilities as the model is highly nonlinear. Hence, we examine these marginal effects by means of probability response curves, as in Bae et al. (2003). These curves show the probabilities of observing a crash of type $j$ at time $t$ as a function of a specific covariate $x_{i t}$. Varying the value of this variable from its minimum to maximum, we compute the average probabilities of observing the different types of crashes across all $T$ observations of the remaining variables $\boldsymbol{x}_{t / i}$. This also allows us to assess the economic significance of our ordered logit regressions, in the sense that the probability response curves provide an indication of the magnitude of the changes in the crash probabilities due to variation in the regressors.

\subsection{Covariates}

We choose the covariates in order to discriminate between a contagious domino effect and interdependence as the underlying reason for the observed dynamics of local, regional and global stock market crashes. To allow for the presence of a domino effect in the evolution of crashes, we include dummy variables for local, regional and global crashes on the previous day. Positive effects of these dummies induce higher probabilities of observing a crash today, if a certain type of crash has occurred in the previous period.

Interdependence effects are incorporated by including several variables that represent information from the currency market, the fixed income market, and short-term interest rates. In our choice of variables, we follow the existing literature, and select to a large extent the same variables as Bae et al. (2003). For the currency markets we use the insight of Cumperayot et al. (2006) that extremes in currency markets and equity markets are related. While the inclusion of economic fundamentals could be useful as shown by Kaminsky and Reinhart (1999), the frequency of marco-economic data does not correspond with the frequency of our observations, and we cannot use them.

For the currency market we follow Bae et al. (2003) and take the average exchange rate returns in Latin America and in Asia. These variables are constructed by taking the 
equally weighted average of the daily log changes in the currencies of all six countries in the region against the US Dollar. We expect a positive effect on the probability of more severe crashes as depreciations lead to a lower value of the stock index. Moreover, depreciations signal net capital outflow, potentially due to a loss of confidence in the emerging markets. The Asian crises serves as a typical example, where the Asian currencies depreciated first, followed by tumbling stock markets.

To investigate whether shocks in the bond market lead to increased crash likelihood we include daily returns (in US dollars) on well diversified regional bond portfolios. These portfolios consist of bonds with long and short maturities, issued by sovereign and quasisovereign entities. We expect a negative effect of emerging market bond returns on crash probabilities. A fall in the prices of government bonds issued by an emerging country may point at a decrease in its creditworthiness and an increase in its default probability. Higher financing costs for the national government will harm economic growth, and a fall of the stock market can be expected. The default of Argentina in 2001 is an example of such a pattern. The US government bond market (and to a lesser extent the European bond market) serves as an international safe haven. So, positive returns on a US government bond portfolio may indicate a flight to quality due to international distress. Therefore, we expect a positive relation between US government bond returns and crash likelihood.

We also include two variables associated with extreme events in the currency and bond markets. Extreme currency depreciations are defined as those depreciations above the 95th quantile of the empirical distribution of currency returns. For the bond market the extreme observations are those below the 5th quantile. The variables are constructed by counting the number of extreme events in the past five days and over the regions. We add these two variables to capture possible overreaction to bad news, not captured by the other currency and bond variables.

The third group of variables consist of three-month interbank interest rates. ${ }^{12}$ Interest rates are on average negatively correlated with stock market returns, as they imply higher costs of capital. For emerging markets, higher interest rates can also be a sign of exchange rate pressure. Higher interest rates are therefore expected to increase crash probabilities.

Finally we include volatility of the stock market itself. We follow the RiskMetrics approach and compute volatility for day $t$ as $\sigma_{t}^{2}=\lambda \sigma_{t-1}^{2}+(1-\lambda) u_{t-1}^{2}$, where $u_{t-1}$ is the demeaned stock market return on the previous day and the decay parameter $\lambda=$ 0.94, (see JPMorgan and Reuters, 1994). We compute the daily volatility on each of the

\footnotetext{
${ }^{12}$ For some emerging market countries we use the one-month interbank interest rate, as the three month interbank interest was not available
} 
four regional stock market indices. Higher volatility increases the probability of extreme negative returns, and therefore we expect a positive relation between volatility and the crash probabilities.

The data is provided by JP Morgan for the fixed income related variables, and by Reuters for the currencies. All the data are obtained from Datastream. All variables are included in the ordered logit model with a lag of one day, such that our models are predictive in nature.

\section{[Insert Table 3 around here]}

Table 3 shows that the correlations between the different groups of covariates are low and often insignificant. ${ }^{13}$ This indicates that the various types of variables provide different and complementary information. Within the different groups some correlations are higher, for instance among the interest rates and stock market volatilities.

\section{Empirical Results}

\subsection{Base Model}

Table 4 reports the estimation results of the ordered logit model for local, regional and global stock market crashes. Panel a shows the coefficient estimates, the log-likelihood and the pseudo- $R^{2}$ of the regression. Panel b provides results on likelihood ratio tests for the joint significance of specific groups of covariates.

\section{[Insert Table 4 around here]}

The first and most important result is that we find strong evidence for the presence of a domino effect. The positive and highly significant coefficients of the previous crash dummies show that crises spread according to a domino effect. This supports our hypothesis that local crashes have a tendency to evolve into more severe crashes through contagion.

To gauge the economic relevance of the domino effect Table 5 reports the crash transition matrix implied by the estimated model. For each combination of current crash type

\footnotetext{
${ }^{13}$ The 5 percent critical values for significance of the correlation coefficients based on a sample of $N=$ 2839 , are -0.04 and 0.04 .
} 
$j$ and previous crash type $i$, we calculate the transition probabilities for all observed values of the other explanatory variables. Table 5 gives the corresponding sample averages. The probabilities in the columns for local, regional and global crashes show the increase in crash likelihood when more severe crashes have occurred. For instance, given that no crash occurred on the previous day, the crash probabilities are equal to 0.21 for a local crash, 0.09 for a regional crash and 0.05 for a global crash. If a local crash occurred on the previous day, crash probabilities become 0.25, 0.12 and 0.06, respectively. So, a crash in a single emerging market provides an important signal of an overall increase in crash risk. A domino of crashing markets may well hit even well-diversified global investors. The domino effect is more pronounced for regional crashes. In this case the regional and global crash probabilities almost double to 0.13 and 0.08 , respectively. After a global crash the probability of a consecutive global crash even triples to 0.13. Regional and local crash probabilities also increase substantially to 0.19 and 0.30 , respectively. The domino effect in the ordered logit model is less prevalent than in the transition matrix in Table $2 \mathrm{~A}$. This may be due to the inclusion of the other financial variables in the model to control for interdependence. However, it is clear that the other financial variables do not subsume the domino effect. Consequently, investors and policy makers should take domino-style contagion into account, as only monitoring financial linkages is not enough.

The significance of the past crash dummies is particularly noteworthy in light of the fact that we include stock market volatility measures in the model. By definition there are more crashes in times of high volatility. As volatilities are persistent and highly correlated across regions, regional and global crashes will occur more frequently when volatilities are high. The patterns in the crash transition matrix in Table 2 could therefore result from global comovement in volatilities. The significance of the crash dummies in the ordered logit model clearly demonstrates the presence of a domino effect.

Second, we detect interdependence by the significant coefficients on the different groups of explanatory variables in Table 4. Part of the occurrence of crashes can be attributed to dependencies with other financial variables that hold in all states of the markets. Interdependence occurs through different channels, since the variables within the group of bond returns, interest rate levels and volatilities are all jointly significant at the 5 percent significance level. ${ }^{14}$ The positive coefficient estimates of the interest rate level and

\footnotetext{
${ }^{14}$ We also considered two relative interest rates: the day-on-day change between two interest rate levels and the difference of the current interest rate level from its three month moving average. For both these variables we do not find significant coefficient estimates. The same holds for extreme changes in interest rates. Results are not shown here to save space, but are available upon request.
} 
volatility variables are in line with our expectations. Higher interest rates significantly increase the probabilities of stock market crashes. Increased stock market volatilities also make extreme returns, and thus crashes, more probable. The coefficient estimates for the variables in these two groups all show the same sign, confirming our hypotheses about these variables. For the bond portfolio returns, we also find the expected signs, negative for Latin America and, Asia and positive for the US. Contrary to the US, the European bond market does not show up as a safe haven. The insignificance may reflect the changing role of the European bond market after the monetary unification. Extreme events in bond markets do not influence crash probabilities significantly.

The currency variables are both insignificant, and a relation between crash probabilities and normal exchange rate movements in the emerging market seems absent. This finding is in contrast to other studies, such as Bae et al. (2003) and Dungey and Martin (2007). Contrary to Bae et al. (2003) we use lagged values for the explanatory variables because our aim is to predict crashes. ${ }^{15}$ Moreover, we want to measure the effect of currency changes on local, regional and global crashes simultaneously, while Bae et al. (2003) examine Asia and Latin America separately. Possibly the extreme currency indicator subsumes all effects of exchange rates on stock market crashes, as its coefficient estimate is highly significant. When we exclude this variable, however, the estimated coefficients for average currency changes remain insignificant. This implies that stock markets only react to substantial depreciations of emerging market currencies. We interpret this finding as another form of contagion, from the currency market to stock markets. As this relation only occurs during crisis periods it cannot qualify as interdependence.

\section{[Insert Figure 1 around here]}

We construct probability response curves to examine the marginal effects of the different regressors in the ordered logit model and to assess their economic significance for the crash probabilities. Figure 1 reports the probability response curves for all individual variables. Additionally, it shows a selected number of joint effects for the interest rate and equity volatility variables. The graphs show that the effects of the different variables on the crash probabilities are economically important. The effects seem larger for the bond market and equity volatility variables than for the currency and interest related variables. For the bond market, except for the US, lower returns lead to higher probabilities of regional and global

\footnotetext{
${ }^{15}$ Using contemporaneous currency changes results in highly significant correctly signed estimates. Results are not reported here but are available upon request.
} 
crashes. For the lowest return on the Latin American bond market this even results in a probability of a global crash equal to 0.25 . The interest rate variables seem to have less influence on stock markets, although the effects are not negligible. The volatilities show a slightly stronger effect than the interest rate variables.

Interest rate levels as well as stock market volatilities are persistent and tend to move together across the different regions (see also the correlations within groups in Table 3). That is, we would expect the US and European equity volatility to move together, for instance. Because the coefficient estimates for these variables also have the same sign, it may be more realistic to assess their effect on the crash probabilities by taking these cross-correlations into account. We therefore show "joint" probability response curves for these variables in Figure 1. The joint volatility response curve is computed by varying the volatilities of the four regions simultaneously between their respective minimums and maximums. For the joint interest response curve we do the same. Here the economic relevance of interest rates and stock market volatilities becomes clear. When all volatilities are high the probability of observing no crash is equal to 0.23 , while there is a probability of 0.44 that a regional or global crash occurs. The joint interest rate curve also shows substantial probabilities of crashes when the interest rates are at a high level simultaneously, as opposed to the marginal effects of individual interest rates.

Knowing to which extent financial variables contribute to severe crashes is important for policy makers as well as investors, as both types of economic agents can benefit from anticipating crashes before they occur. Although this is not directly related to contagion in the sense of crashes spreading from local to regional and even global, our results suggest that instability of exchange rates and bond markets as well as high levels of interest rates and stock market volatility provide important "early warning signals" that may be used to avoid more severe crashes.

The extreme currency and bond market graphs indicate the presence of contagion from other markets to the stock market. For the extreme currency depreciations this effect is stronger than for the bond market. The probability of a global crash increases from 0.03 to 0.08 as the number of extreme depreciations increase from 0 to 6 , indicating the influence of emerging currencies on global stock markets.

Finally, for the estimates of the threshold parameters $\alpha_{j}$ we use a Wald test to determine whether each $\alpha_{j}$ is significantly different from its adjacent thresholds $\alpha_{j-1}$ and $\alpha_{j+1}$. We find that this is indeed the case and therefore the distinction between the four crash types seems appropriate. The pseudo- $R^{2}$ is equal to 0.07 , which is comparable to other 
studies that consider forecasting models for crashes. This indicates that the explanatory variables have some predictive power with respect to crashes. We also examine whether there is autocorrelation in the residuals and we find that there is hardly any left, which is important as the estimation of the ordered logit model assumes conditional independence.

\subsection{Conditional effects}

Our base model provides evidence for both interdependence and contagion. In this section we explore whether the effects of the financial variables on the crash probabilities are dependent on the occurrence of a particular type of crash on the previous day. If, for example, the relations between the financial variables and the crash probabilities are found to be stronger in times of turmoil, this can be interpreted as excessive dependence in financial markets. This may be then be considered as a mixed form of contagion and interdependence.

From the results of this analysis (discussed in Appendix A) we conclude that there is no evidence for such conditional effects. The relations between the financial variables and the crash probabilities are stable, in the sense that they do not depend on the prior occurrence of crashes. There is, however, one exception: average currency depreciations in Latin American, which are insignificant in the base model, have a significant positive effect on crash likelihood when a global crash occurred on the previous day.

\subsection{Robustness checks}

We perform several checks to assess the robustness of the substantial role that the domino effect plays in the transmission of stock market crashes.

\subsubsection{Multinomial logit}

We check the appropriateness of using an ordered logit model by formally testing it against a multinomial logit model. We perform the likelihood ratio test for non-nested model selection of Vuong (1989) as well as an alternative distribution-free test introduced by Clarke (2007). Both tests are based on the Kullback-Leibler information criterion (KLIC), which measures the distance from the true, unknown specification. The difference in KLIC is the expected value of the (log) likelihood ratio,

$$
E_{0}\left[\log \frac{f_{\mathrm{o}}\left(y_{t} \mid \boldsymbol{x}_{t} ; \boldsymbol{\theta}_{\mathrm{o}}\right)}{f_{\mathrm{m}}\left(y_{t} \mid \boldsymbol{x}_{t} ; \boldsymbol{\theta}_{\mathrm{m}}\right)}\right],
$$


taken with respect to the true distribution, where $f_{\mathrm{o}}\left(y_{t} \mid \boldsymbol{x}_{t} ; \boldsymbol{\theta}_{\mathrm{o}}\right)$ and $f_{\mathrm{m}}\left(y_{t} \mid \boldsymbol{x}_{t} ; \boldsymbol{\theta}_{\mathrm{m}}\right)$ denote the likelihood functions of the ordered and multinomial models, respectively, and $\boldsymbol{\theta}_{\mathrm{o}}$ and $\boldsymbol{\theta}_{\mathrm{m}}$ their respective parameter vectors. The Vuong test for the null hypothesis $H_{0}$ : $E_{0}\left[\log \left(f_{\mathrm{o}}\left(y_{t} \mid \boldsymbol{x}_{t} ; \boldsymbol{\theta}_{\mathrm{o}}\right) / f_{\mathrm{m}}\left(y_{t} \mid \boldsymbol{x}_{t} ; \boldsymbol{\theta}_{\mathrm{m}}\right)\right)\right]=0$ is given by

$$
\frac{L R_{T}\left(\hat{\boldsymbol{\theta}}_{\mathrm{o}}, \hat{\boldsymbol{\theta}}_{\mathrm{m}}\right)-\frac{1}{2}\left(k_{\mathrm{o}}-k_{\mathrm{m}}\right) \ln T}{\sqrt{T \hat{\omega}^{2}}}
$$

where $L R_{T}\left(\hat{\boldsymbol{\theta}}_{\mathrm{o}}, \hat{\boldsymbol{\theta}}_{\mathrm{m}}\right)$ is the summed log-likehood ratio for the sample of $T$ observations based on parameter estimates $\hat{\boldsymbol{\theta}}_{\mathrm{o}}$ and $\hat{\boldsymbol{\theta}}_{\mathrm{m}}, \hat{\omega}^{2}$ is an estimate of the variance given by

$$
\hat{\omega}^{2}=\frac{1}{T} \sum_{t=1}^{T}\left[\log \frac{f_{\mathrm{o}}\left(y_{t} \mid \boldsymbol{x}_{t} ; \hat{\boldsymbol{\theta}}_{\mathrm{o}}\right)}{f_{\mathrm{m}}\left(y_{t} \mid \boldsymbol{x}_{t} ; \hat{\boldsymbol{\theta}}_{\mathrm{m}}\right)}\right]^{2}-\left[\frac{1}{T} \sum_{t=1}^{T} \log \frac{f_{\mathrm{o}}\left(y_{t} \mid \boldsymbol{x}_{t} ; \hat{\boldsymbol{\theta}}_{\mathrm{o}}\right)}{f_{\mathrm{m}}\left(y_{t} \mid \boldsymbol{x}_{t} ; \hat{\boldsymbol{\theta}}_{\mathrm{m}}\right)}\right]^{2} .
$$

The second term in the denominator in (5) is a correction term for the different numbers of parameters in the in the ordered and multinomial models, where in our case $k_{\mathrm{o}}=22$ and $k_{\mathrm{m}}=60$. The Vuong statistic converges in distribution to $N(0,1)$.

Clarke (2007)'s distribution-free test is based on the null hypothesis that,

$$
\operatorname{Pr}\left[\log \frac{f_{\mathrm{o}}\left(y_{t} \mid \boldsymbol{x}_{t} ; \boldsymbol{\theta}_{\mathrm{o}}\right)}{f_{\mathrm{m}}\left(y_{t} \mid \boldsymbol{x}_{t} ; \boldsymbol{\theta}_{\mathrm{m}}\right)}>0\right]=0.5
$$

which reflects the fact that if both models are equally close to the true specification, the likelihood function of the ordered logit model should exceed that of the multinomial model for half of the observations. The corresponding test statistic is given by

$$
B=\sum_{t=1}^{T} I\left[\log \frac{f_{\mathrm{o}}\left(y_{t} \mid \boldsymbol{x}_{t} ; \boldsymbol{\theta}_{\mathrm{o}}\right)}{f_{\mathrm{m}}\left(y_{t} \mid \boldsymbol{x}_{t} ; \boldsymbol{\theta}_{\mathrm{m}}\right)}-\frac{1}{2}\left(k_{\mathrm{o}}-k_{\mathrm{m}}\right) \ln T>0\right]
$$

where $I[]$ is an indicator function taking the value one if its argument is true. Asymptotically, the $B$-statistic has a binomial distribution with parameters $T$ and $p=0.5$.

We calculate both statistics for comparing the ordered logit model discussed in the previous section to a multinomial model with the same covariates $\boldsymbol{x}_{t}$. The Vuong test statistic attains a value of 10.55 with a $p$-value of 0.00 , which means that the multinomial logit model is strongly rejected. The distribution free test statistic equals 0.73 (meaning that for 73 percent of the observations the likelihood for the ordered model is larger than that of the multinomial model), with a $p$-value of 0.00 . Based on these test results we 
conclude that our ordered model is better able to describe the occurrence of stock market crashes than the multinomial model.

\subsubsection{Alternative ordered regression specifications}

To test the robustness of our specification we implement four alternative regressions. First, our results may be influenced by time-varying volatility, as we work with raw daily returns. We redo the crash classification and then estimate the ordered logit model using standardized returns. Table 6 shows that, except for the volatility coefficients, the results do not change substantially. This is in line with the preliminary results from the crash transition matrices in Table 2. In particular, the coefficients of the previous day crash dummies remain highly significant. We conclude that the domino effect is not driven by time-varying volatility in the stock market.

\section{[Insert Table 6 around here]}

As a second robustness check we use the 2.5th quantile instead of the 5th quantile to define crashes. Obviously, this leads to less crashes for each individual market and, consequently, also less local, regional and global crashes. Table 6 shows that the ordered logit results are not sensitive to this alternative crash definition. For the domino effect, we find that the coefficients of the dummies for local and global crashes on the previous day remain virtually the same as in the base model. The coefficient for regional crashes declines from 0.62 to 0.33 while its $p$-value increases from 0.00 to 0.08 .

Our final two robustness checks are based on variations in the definitions of regional and global crashes as explained in Section 2.2. In the first alternative classification we do not identify a global crash in case a regional crash occurs in Asia on day $t+1$ following a regional crash in the US or Europe on day $t$. Furthermore, we also abandon the occurrence of regional emerging market crashes when four or more individual emerging markets in a particular region crash. In the second alternative classification a global crash occurs when three or four regions crash instead of two (from which one has to be developed). Though both settings are stricter, the estimation results using these alternative classifications hardly differ from the original one, see Table 6 . In both cases, the coefficients of the

previous day crash dummies remain highly significant, with magnitudes comparable to the base model. Hence, our conclusions regarding the domino effect are not affected.

In sum, the various robustness checks in this section demonstrate that our results are 
not due to the effects of time-varying volatility, and are not driven by arbitrary choices for the crash definitions and crash classifications.

\section{Comparison with binomial model for global crashes}

In this section we assess the economic relevance of the domino effect and our modelling approach. If relevant, including local and regional crashes should help forecasting global crashes. We address this issue by comparing our ordered logit model with a binomial logit model for global crashes only. For the latter model we combine the days with no crash, local crash or regional crash into a single "no global crash" state. Redefining the variable $y_{t}$ to be equal to one when a global crash occurs and zero otherwise, the probability of a global crash in the binomial logit model is given by

$$
p_{t}=\operatorname{Pr}\left(y_{t}=1\right)=\frac{e^{\left(\tilde{\boldsymbol{x}}_{t}^{\prime} \boldsymbol{\beta}_{b}\right)}}{1+e^{\left(\tilde{\boldsymbol{x}}_{t}^{\prime} \boldsymbol{\beta}_{b}\right)}},
$$

where the vector $\tilde{\boldsymbol{x}}_{t}$ includes the same financial variables as used in the ordered logit model plus a constant, but not the dummy variables for local and regional crashes occurring on the previous day.

\subsection{In-sample comparison}

The estimation results for the binomial model in Table 7

reveal several advantages of using the refined crash classification instead of a binomial approach. First, the coefficients in the ordered logit model as shown in Table 4 are estimated with considerably more precision, with standard errors being only half as large on average. For instance, the standard errors of the two extreme event coefficient estimates are 0.05 and 0.03 for the ordered model against 0.10 and 0.06 for the binomial model. Second, the ordered model shows more consistency concerning the signs of the coefficient estimates across different regions. For the interest rate and the equity volatility variables, we find that the estimated coefficients have the same sign for all four regions in the ordered model, while in the binomial model signs differ within these groups of variables. Including separate states for local and regional crashes thus increases the precision and the interpretability of the coefficient estimates for the explanatory variables. 


\section{[Insert Table 7 around here]}

The ordered logit model explicitly uses the local and regional crashes in the parameter estimation, which obviously increases the total number of observed crashes. In this way it avoids a weakness of binomial crash models, namely that crashes occur too infrequently to estimate contagion and interdependence effects with sufficient precision. On the other hand the results in Section 4 show that the ordered model is still capable of distinguishing global crashes from less severe crashes.

\section{[Insert Figure 2 around here]}

Figure 2 shows the implied probabilities of observing a global crash obtained from the binomial model and the ordered logit model, as well as the observed global crashes. The ordered model for local, regional and global crashes leads to a better performance in detecting global crashes than only accounting for global crashes in the model. Especially periods in which global crashes are clustered are better detected, see for example the effects of the 1997 Asian crisis and the 1998 Russian debt crisis. Furthermore, around the burst of the internet bubble (March, 2000) the ordered model clearly shows increased global crash probabilities, while the binomial model hardly indicates any turmoil in financial markets. During the turbulent period between 2001 and 2003 the binomial model produces somewhat higher global crash probabilities than the ordered model. However, in those periods the ordered model's crash probabilities are also relatively high. After 2003 less global crashes occurred, but for the crashes that did occur, the ordered model is more successful in detecting them than the binomial model. This holds in particular for the period between December 2003 and December 2005.

\subsection{Out-of-sample comparison}

Next we examine the out-of-sample predictive accuracy of the ordered logit model, relative to the binomial model. We use the period July 1996 till December 2001 for specifying and estimating both models, and leave the period January 2002 till July 2007 for forecast evaluation. ${ }^{16}$ Based on the conventional wisdom that large models with many insignifi-

\footnotetext{
${ }^{16}$ We avoid using information from the out-of-sample period in the specification and estimation of the models by recomputing our dependent variable based on the 5th quantile of the empirical return distribution over the period till December 2001. The same applies to the regressors representing extreme events in the currency and bond markets.
} 
cant parameters often lead to bad forecasting performance, we apply a variable selection procedure to reduce the number of covariates. ${ }^{17}$ For both the ordered and binomial models we start with the full model and eliminate the least significant variable. Then the model is re-estimated and again the least significant variable is removed. This process is continued until the coefficients for all remaining variables are significant at the $10 \%$ level. ${ }^{18}$

\section{[Insert Table 8 around here]}

Table 8 reports the results from this general-to-specific model selection procedure for both models. We observe that for both models the number of regressors is drastically reduced, though the ordered model contains somewhat more variables. Besides the previous crash dummies, which are all significant in both models, the ordered model contains six financial variables, while in the binomial model only four variables are included. This could be expected as the ordered model's estimates are more precise, as discussed in the previous section.

Forecasts of the probability of a global crash for the period January 2002 - July 2007 are displayed in Figure 3. The ordered model is clearly more successful than the binomial model in forecasting global crashes. The period May 2002 till June 2003 contains many global crashes. At the beginning of this period our ordered model already correctly warns for the occurrence of global crashes, while the binomial model's crash probabilities hardly increase. Then, during the period between July and October 2002, for both models the global crash probability forecasts strongly increase, taking values above 0.4 . In this period both models are able to forecast the global crashes that occurred. After October 2002 the turmoil in the global financial markets continues, as indicated by the substantial number of global crashes that occur. During this period, the ordered model again forecasts the global crashes better than the binomial model. Finally, after 2003 some shorter periods with global crashes occurred and in all these cases the ordered model indicates this correctly, contrary to the binomial model.

\section{[Insert Figure 3 around here]}

\footnotetext{
${ }^{17}$ Coefficient estimates in the full model over the sample July 1996 till December 2001 are comparable to Table 4, but standard errors are substantially larger. These results are available on request.

${ }^{18}$ Stricter significance levels would result in models with too few explanatory variables to make a fair comparison between the ordered and binary models.
} 
To further analyze the differences in forecasting performance we compute the quadratic probability score (QPS), hit rates, false alarm rates and the Kuipers score, (see for example Granger and Pesaran, 2000). The QPS is defined as

$$
\mathrm{QPS}=\frac{1}{P} \sum_{t=R+1}^{T}\left(f_{t}-y_{t}\right)^{2},
$$

where $f_{t}$ is the probability forecast for time $t$ and $y_{t} \in\{0,1\}$ is the corresponding realization, $R$ and $P$ are the number of observations in the in-sample and out-of-sample periods, with $R+P=T$. The QPS varies between zero and one, indicating perfect and no forecasting performance, respectively. For the binomial and ordered models, the QPS attains the value 0.0262 and 0.0260 , indicating a slightly better forecast performance for the ordered logit model, although the difference seems negligible. Since global crashes are rare, the QPS is dominated by the frequent observations of no global crash. To focus on the ability of the models to forecast global crashes, we examine their hit rates and false alarm rates. The hit rate is defined as the fraction of crashes that were correctly predicted, while the false alarm rate is defined as the fraction of days without a global crash for which a crash was predicted to occur. Obviously, computing the hit rate and false alarm rate requires a cut-off level $w$, such that probability forecasts larger than $w$ are taken to be predictions of a crash. We vary $w$ between 0 and 0.20 with increments of 0.01 , to examine the sensitivity of the forecast performance to this cut-off level.

\section{[Insert table 9 around here]}

Table 9 shows the hit rates and false alarm rates for the different values of $w$. Also shown is the Kuipers score, defined as the difference between the hit rate and the false alarm rate. Both models attain the highest Kuipers score for $w=0.03$, with values equal to 0.546 for the ordered model and 0.535 for the binomial model. Again, the ordered model has slightly better predictive accuracy. It is useful to note that the underlying hit rates and false alarm rates differ substantially though, and are equal to 0.732 and 0.197 for the binomial model, and 0.927 and 0.381 for the ordered model. This means that for the optimal Kuipers score the ordered model predicts almost all global crashes (93 percent) correctly, which comes at the expense of a substantial number of false alarms (38 percent). The binomial model predicts only 73 percent of the crashes correctly, with 20 percent false alarms. If missing a global crash is more costly than a false alarm, which is likely to be 
the case in practice, the ordered logit approach is clearly to be preferred. This conclusion actually also holds if false alarm rates were relatively expensive. In that case, we could choose, for instance, a cutoff level of 0.08 for the ordered logit model, giving a false alarm rate of only 7.2 percent and a hit rate of 59 percent. To compare this with the binomial model we might take $w=0.06$, which results in a comparable false alarm rate (7.6 percent), at the cost of a 10 percent (58.5-48.8) lower hit rate.

\section{Conclusions}

In this paper we have investigated whether stock market crashes propagate from local to regional and global levels through a domino effect. Using daily returns for a sample of emerging and developed stock markets for the period July 1996 - July 2007, we classified crashes as local, regional or global. This classification was used in an ordered logit regression framework to examine the propagation of stock market crashes, and the relevance of interdependence and contagion effects. Our approach differs from other studies by explicitly defining different types of crashes, and modelling their transmission mechanism as a domino effect.

We report evidence that less severe crashes tend to be followed by more severe crashes. The probabilities of a regional or global crash occurring tomorrow increase significantly and substantially when a local (or regional) crash occurs today. In explaining the occurrence and evolution of crashes we also find evidence for interdependence between stock markets and other asset markets. Information from the currency, stock and bond markets are important determinants of the probabilities to end up in a local, regional or global crash. Our out-of-sample analysis confirms the superiority of the ordered model that includes local and regional crashes in forecasting global crashes to a standard binomial model.

The domino effect that we report holds an important lesson for investors and regulators. On the one hand, it stresses again the danger of contagion in financial markets, as it exists beyond dependencies and linear autocorrelation that dominate normal periods. On the other hand, the domino effect can be used to improve early-warning systems. Besides the statistical evidence for incorporating the domino effect, we also document its economic relevance. If failing to forecast global crashes is more costly than giving a false alarm, the ordered model with the domino effect outperforms the binomial model without it. If the false alarm rate should be kept at reasonable levels, to limit reputational damage for example, the ordered model does a better job as well. Concluding, because of their 
susceptibility to macroeconomic shocks, emerging markets can be the point of origin of an eventually global crash. Therefore, all investors and regulators should keep an eye on what happens in these markets, whether they are directly exposed to it or not. 


\section{References}

Bae, K., Karolyi, A., and Stulz, R. (2003). A New Approach to Measuring Financial Contagion. Review of Financial Studies, 16:717-763.

Boyer, B., Gibson, M., and Loretan, M. (1999). Pitfalls in Tests for Changes in Correlations. Federal Reserve Board of Governors International Finance Discussion Papers, No. 597.

Boyer, B., Kunagai, T., and Yuan, K. (2006). How Do Crises Spread? Evidence from Accessible and Inaccessible Stock Indices. Journal of Finance, 61:957-1003.

Christiansen, C. and Ranaldo, A. (2009). Extreme Coexceedances in New EU Member States Stock Markets. Journal of Banking and Finance, 33:1048-1057.

Clarke, K. (2007). A Simple Distribution-Free Test for Nonnested Model Selection. Political Analysis, 15:347-363.

Connolly, R. and Wang, F. (2003). International Equity Market Comovements: Economic Fundamentals or Contagion? Pacific-Basin Finance Journal, 11:23-43.

Cumperayot, P., Keijzer, T., and Kouwenberg, R. (2006). Linkages Between Extreme Stock Market and Currency Returns. Journal of International Money and Finance, 25:528-555.

Dornbusch, R., Park, Y., and Claessens, S. (2000). Contagion: How It Spreads and How It Can Be Stopped. World Bank Research Observer, 15:177-197.

Dungey, M., Fry, R., and B. Gonzlez-Hermosillo, a. V. M. (2005). Empirical Modelling of Contagion: A Review of Methodologies. Quantitative Finance, 5:9-24.

Dungey, M., Fry, R., Gonzlez-Hermosillo, B., Martin, V., and Tang, C. (2008). Are Financial Crises Alike? CAMA working paper 2008-15.

Dungey, M. and Martin, V. (2007). Unravelling Financial Market Linkages During Crises. Journal of Applied Econometrics, 22:89-119.

Favero, C. and Giavazzi, F. (2002). Is the International Propagation of Financial Shocks Non-Linear? Evidence from the ERM. Journal of International Economics, 57:231-246.

Fazio, G. (2007). Extreme Interdependence and Extreme Contagion Between Emerging Markets. Journal of International Money and Finance, 26:1261-1291.

Forbes, K. and Rigobon, R. (2002). No Contagion, Only Interdependence: Measuring Stock Market Comovements. Journal of Finance, 57:2223-2261.

Granger, C. and Pesaran, M. (2000). Economic and Statistical Measures of Forecast Acurracy. Journal of Forecasting, 19:537-560. 
Hamao, Y., Masulis, R., and Ng, V. (1990). Correlations in Price Changes and Volatility Across International Stock Markets. Review of Financial Studies, 3:281-307.

Hartmann, P., Straetmans, S., and De Vries, C. (2004). Asset Market Linkages in Crisis Periods. Review of Economics and Statistics, 86:313-326.

JPMorgan and Reuters (1994). Riskmetrics technical document. Morgan Guaranty Trust Company, New York.

Kamin, S. (1999). The Current International Financial Crisis: How Much is New? Journal of International Money and Finance, 18:501-514.

Kaminsky, G. and Reinhart, C. (1999). The Twin Crises: The Causes of Banking and Balance-Of-Payments Problems. American Economic Review, 98(3):473-500.

Kaminsky, G. and Schmukler, S. (1999). What Triggers Market Jitters? Journal of International Money and Finance, 18:537-560.

King, M. and Wadhwani, S. (1990). Transmission of Volatility between Stock Markets. Review of Financial Studies, 3:5-33.

Kleimeier, S., Lehnert, T., and Verschoor, W. (2008). Measuring Financial Contagion Using Time-Aligned Data: The Importance of the Speed of Transmissions of Shocks. Oxford Bulletin of Economics and Statistics, 70:493-508.

Kose, M., Otrok, C., and Whiteman, C. (1990). International Business Cycles: World, Region, and Country-Specific Factors. American Economic Review, 93:1216-1239.

Lee, S. and Kim, K. (1993). Does the October 1987 Crash Strengthen the Comovements Among National Stock Markets? Review of Financial Economics, 3:89-102.

Longin, F. and Solnik, B. (1995). Is the Correlation in International Equity Returns Constant: 1960-1990? Journal of International Money and Finance, 14:3-26.

Longin, F. and Solnik, B. (2001). Extreme Correlations of International Equity Markets. Journal of Finance, 56:649-676.

Loretan, M. and English, W. (2000). Evaluating "Correlation Creakdowns" During Periods of Market Volatility. In International Financial Markets and the Implications for Monetary and Financial Stability, pages 214-231. Bank for International settlements, Basel, Switzerland.

McFadden, D. (1974). The Measurement of Urban Travel Demand. Journal of Public Economics, 3:303-328.

Ng, A. (2000). Volatility Spillover Effects from Japan and the US to the Pacific-Basin. Journal of International Money and Finance, 19:207-233. 
Pericoli, M. and Sbracia, M. (2003). A Primer on Financial Contagion. Journal of Economic Surveys, 17:1139-1180.

Politis, D. and Romano, J. (1994). The Stationary Bootstrap. Journal of the American Statistical Association, 89:1303-1313.

Politis, D. and White, H. (2004). Automatic Block-Length Selection for the Dependent Bootstrap. Econometric Reviews, 23:53-70.

Rodriquez, J. (2007). Measuring Financial Contagion: A Copula Approach. Journal of Empirical Finance, 14:401-432.

Vuong, Q. (1989). Likelihood Ratio Tests for Model Selection and Non-Nested Hypotheses. Econometrica, 57:307-333.

\section{Appendix A: Conditional Effects}

In this appendix we discuss the results obtained from the ordered logit model with conditional effects, that is, the effects of financial variables on the crash probabilities are allowed to be dependent on past crashes. To test for the presence of this mixed type of interdependence and contagion, we proceed as follows. We interact one of the financial variables $x_{i t}$ in the model with the different past crash dummy variables. Thus we obtain four state dependent variables $x_{i t} D_{j t} \equiv x_{i t \mid j}$, where $D_{j t}$ is a dummy variable taking the value one if crash type $j$ occurs at time $t-1$ and zero otherwise. We estimate an ordered logit model including these four new conditional variables and the other variables in their original form. We repeat this procedure for each of the financial variables included in the model, resulting in sixteen separate ordered logit regressions. The reason for not estimating a model which has coefficients varying with the crash type for all financial variables simultaneously is the large number $(16 \times 4+3+3+1=71)$ of coefficients.

If this intermediate form of interdependence and contagion were relevant, we would expect to find clear patterns in the estimates of the state-dependent coefficients. For instance, for the average currency change variables we expect the coefficients to become more negative conditional on more severe crashes, as this implies that the higher the turmoil, the stronger the relation between stock market crashes and currency changes.

To formally examine whether this extension of the model leads to better description of the observed crashes, we perform likelihood ratio (LR) tests for the null hypothesis that the coefficients $\beta_{i \mid j}, j=0,1,2,3$, of the state-dependent variables are equal. This test statistic is $\chi^{2}$ distributed with three degrees of freedom, corresponding to three parameter restrictions $\beta_{i \mid 0}=\beta_{i \mid 1}=\beta_{i \mid 2}=\beta_{i \mid 3}$.

\section{[Insert Table 10 around here]}


Table 10 reports the estimates of the state-dependent parameters for the sixteen estimated regression models together with the $p$-value of the LR test for their equality. To save space we do not report the estimates of the other coefficients in these models. ${ }^{19}$ In general we do not observe clear patterns in the estimates of the state-dependent coefficients. In fact, for almost all variables the conditional estimates fluctuate around the coefficient estimate in the base model in a seemingly random fashion. In addition, except for the bond returns and the volatility variable in Asia, the LR tests do not reject the null of equality of the conditional coefficients, confirming that the relations between crashes and the financial variables are not dependent on past crashes. Put differently, the effects of the financial variables on the crash probabilities do not depend on the degree of turmoil in the financial markets. Thus we find no evidence of this intermediate type of contagion and interdependence.

However, there are some interesting but also counterintuitive results in Table 10. First, while the average currency depreciation in Latin America was not significant in the base model, this relation becomes significant when a global crash has occurred on the previous day. For the average currency depreciation in Asia we observe the same pattern, but here the coefficients are not significant. It seems that normal currency depreciations increase the crash probabilities only if a global crash occurred on the previous day. Thus, in times of high turmoil investors also seem to take into account normal depreciations.

In the conditional regressions for the interest rates some past crash dummies become insignificant, while the interest rate variables remain insignificant. To a lesser extent this occurs for equity volatility too. This has a more statistical than economic cause: as the interest rates and volatilities are strictly positive, the dummy variables and their respective conditional variables attain the value zero or a value larger than zero simultaneously. This results in very high correlations of around 0.95 between the past crash dummies and the conditional variables.

\footnotetext{
${ }^{19}$ The estimates of the other coefficients hardly change compared to the base model in Table 4.
} 


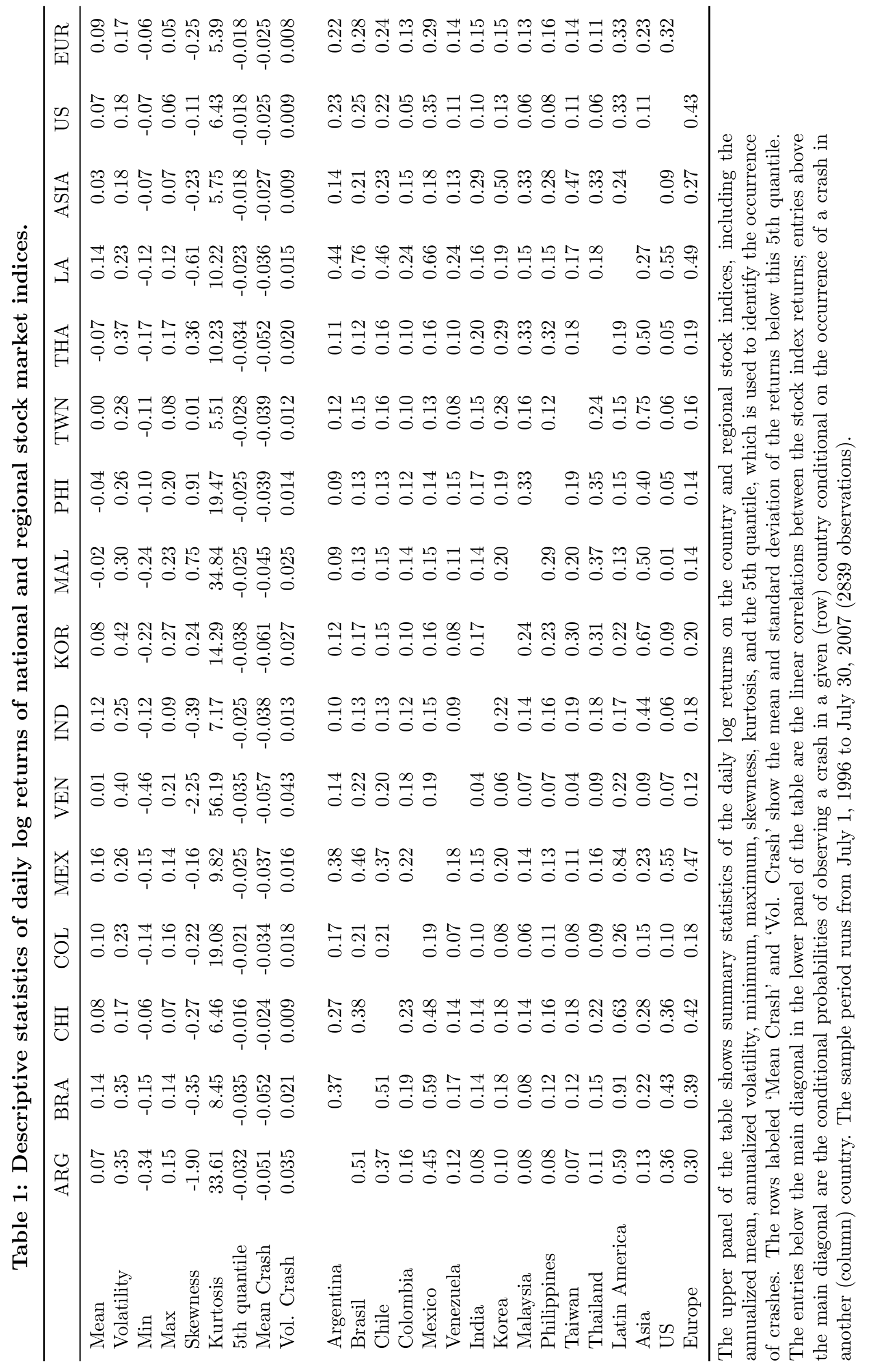


Figure 1: Probability response curves
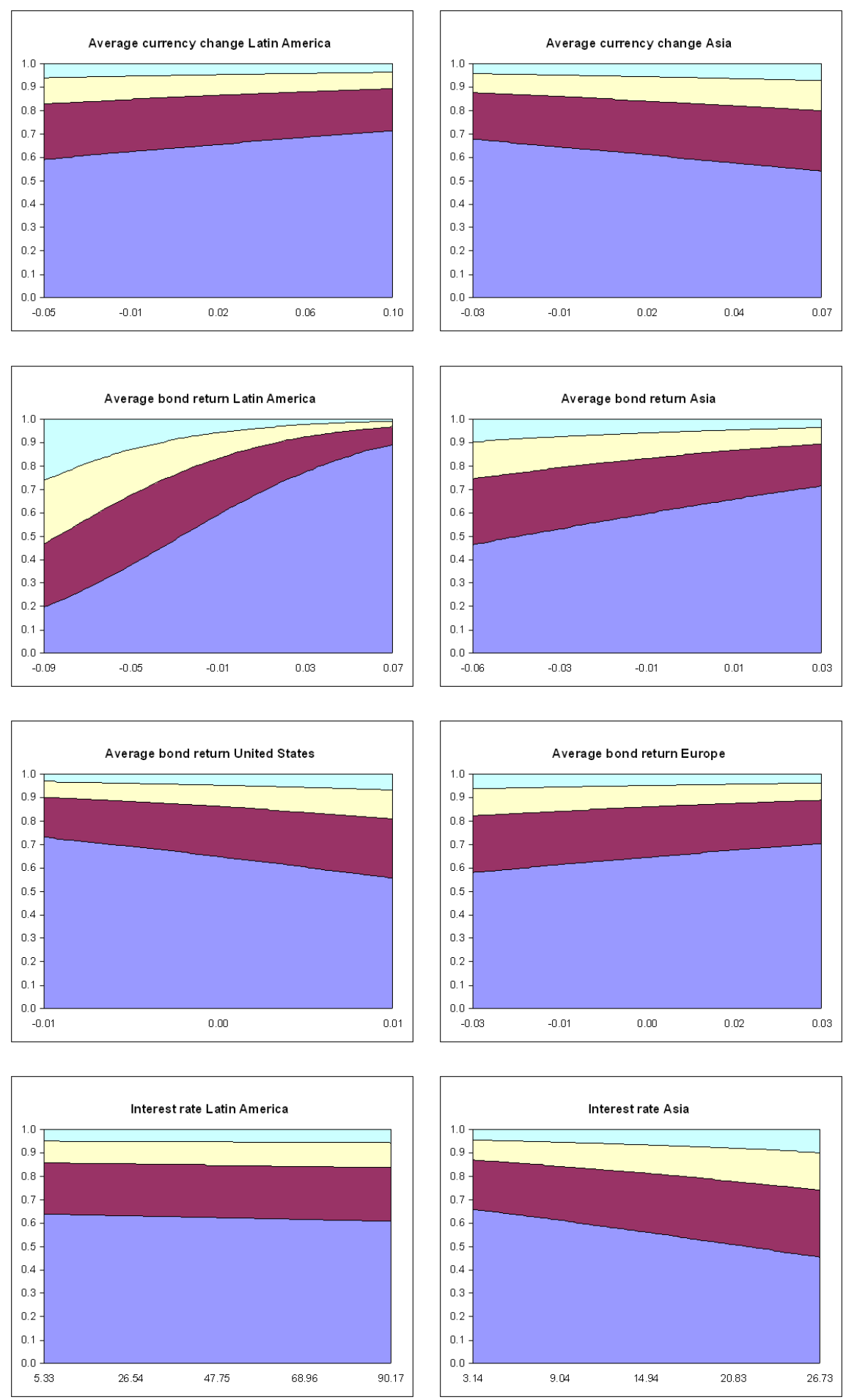
Figure 1: Probability response curves, continued
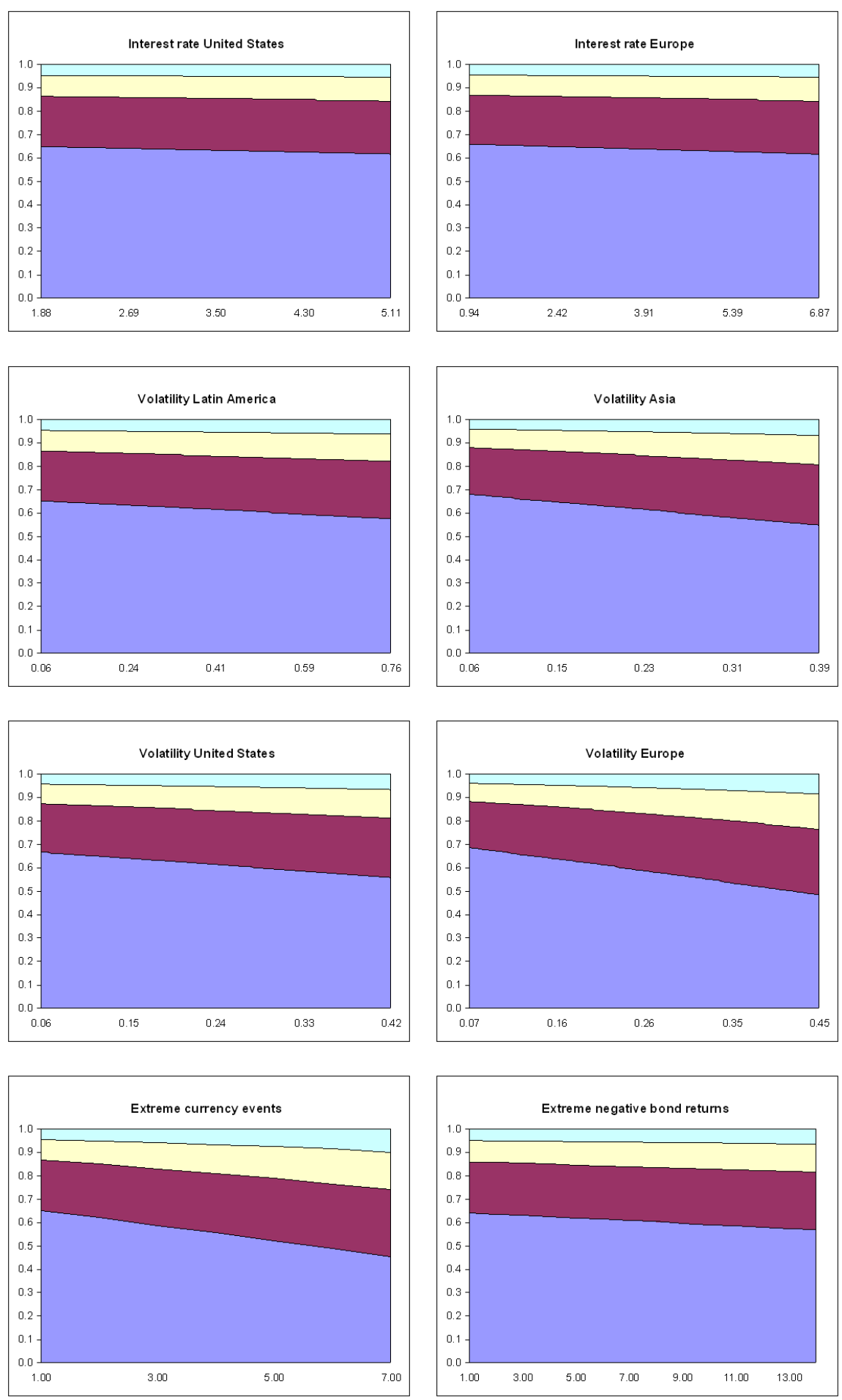
Figure 1: Probability response curves, continued
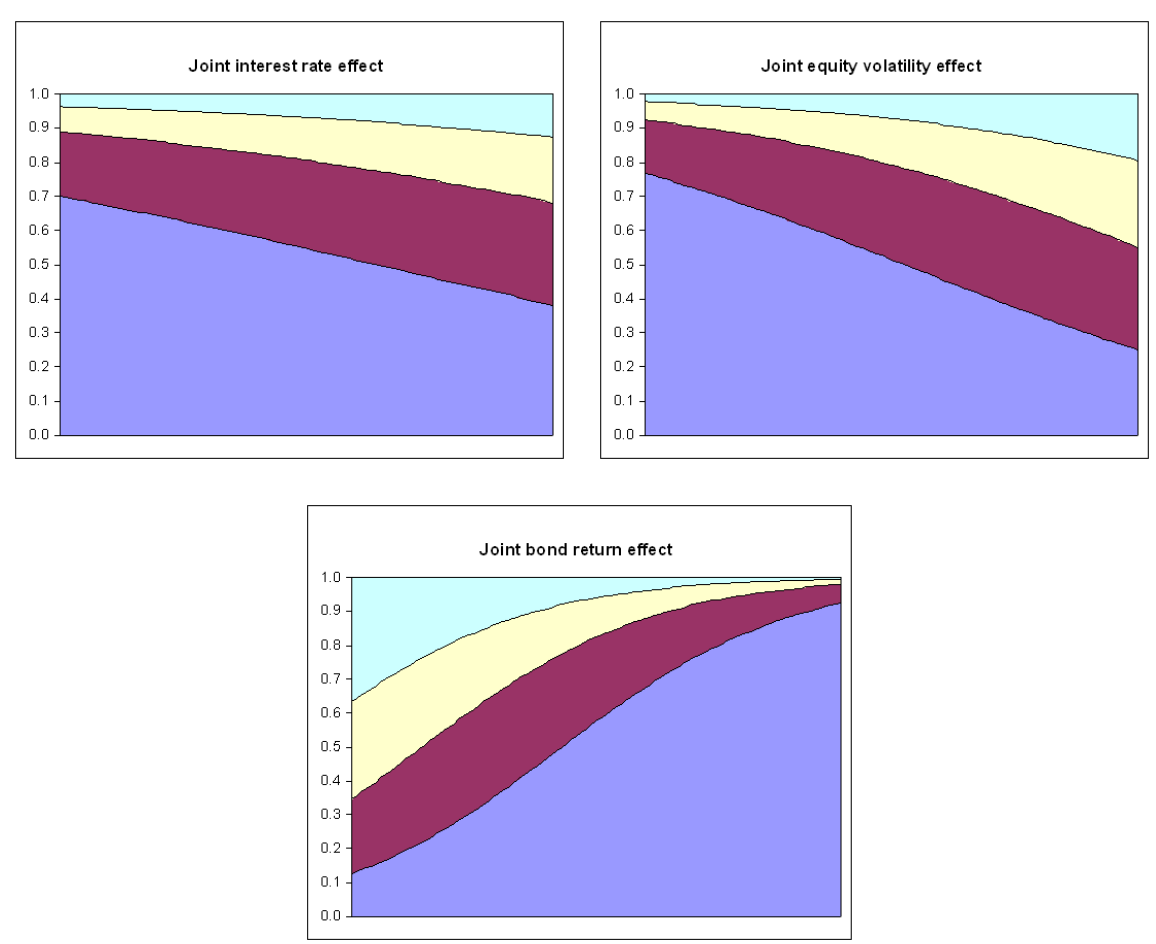

\section{No Crash $\square$ Local Crash $\square$ Regional Crash $\square$ Global Crash}

The graphs show the probability response curves in the ordered logit regression model reported in Table 4. The areas are the probabilities of observing a specific type of crash. The probabilities are computed by varying one specific variable $x_{i t}$ from its minimum to maximum. Then for each point on the probability response curve, we compute the probabilities of observing a type of crash for all $T$ observations of the remaining variables $x_{t / i}$. The joint response graphs for interest rates and equity volatility are computed by varying all four variables between their respective minimum and maximum simultaneously. 
Table 2: Crash transition probabilities

\begin{tabular}{ccccc}
\hline \multicolumn{5}{c}{ A: Raw returns } \\
& $\mathrm{N}$ & $\mathrm{L}$ & $\mathrm{R}$ & $\mathrm{G}$ \\
\hline $\mathrm{N}$ & 0.72 & 0.19 & 0.07 & 0.03 \\
$\mathrm{~L}$ & 0.57 & 0.27 & 0.10 & 0.06 \\
$\mathrm{R}$ & 0.45 & 0.27 & 0.17 & 0.11 \\
$\mathrm{G}$ & 0.27 & 0.23 & 0.29 & 0.20 \\
\hline
\end{tabular}

B: Standardized returns

C: Bootstrapped raw returns

\begin{tabular}{ccccc} 
& $\mathrm{N}$ & $\mathrm{L}$ & $\mathrm{R}$ & $\mathrm{G}$ \\
\hline $\mathrm{N}$ & 0.68 & 0.20 & 0.08 & 0.04 \\
$\mathrm{~L}$ & 0.61 & 0.24 & 0.10 & 0.05 \\
$\mathrm{R}$ & 0.55 & 0.25 & 0.13 & 0.07 \\
$\mathrm{G}$ & 0.44 & 0.22 & 0.21 & 0.13
\end{tabular}

\begin{tabular}{ccccc} 
& $\mathrm{N}$ & $\mathrm{L}$ & $\mathrm{R}$ & $\mathrm{G}$ \\
\hline $\mathrm{N}$ & 0.71 & 0.19 & 0.08 & 0.02 \\
$\mathrm{~L}$ & 0.56 & 0.29 & 0.10 & 0.05 \\
$\mathrm{R}$ & 0.51 & 0.24 & 0.16 & 0.09 \\
$\mathrm{G}$ & 0.23 & 0.24 & 0.30 & 0.22
\end{tabular}

D: Bootstrapped standardized returns

\begin{tabular}{ccccc} 
& $\mathrm{N}$ & $\mathrm{L}$ & $\mathrm{R}$ & $\mathrm{G}$ \\
\hline $\mathrm{N}$ & 0.68 & 0.20 & 0.09 & 0.03 \\
$\mathrm{~L}$ & 0.60 & 0.25 & 0.10 & 0.05 \\
$\mathrm{R}$ & 0.58 & 0.23 & 0.13 & 0.06 \\
$\mathrm{G}$ & 0.41 & 0.23 & 0.23 & 0.13 \\
\hline
\end{tabular}

The four panels in this table contain crash transition probabilities, where the $i j$-th element is the probability of observing the state in column $j$, given that on the previous day the state in row $i$ occurred. The row and column labels N, L, R, and G correspond to no crash, local, regional and global crash, respectively. Panels $\mathrm{A}$ and $\mathrm{B}$ are based on the crashes identified in the series of raw and standardized returns, respectively, of the twelve emerging market country indices and four regional indices over the sample period July 1, 1996 - July 30, 2007 ( $T=2839$ observations), using the classification rules explained in Section 2.2. Panels C and $\mathrm{D}$ show the average transition matrices computed from 10,000 bootstrap samples of length $T$ obtained by the stationary bootstrap for the raw and standardized returns, respectively. 


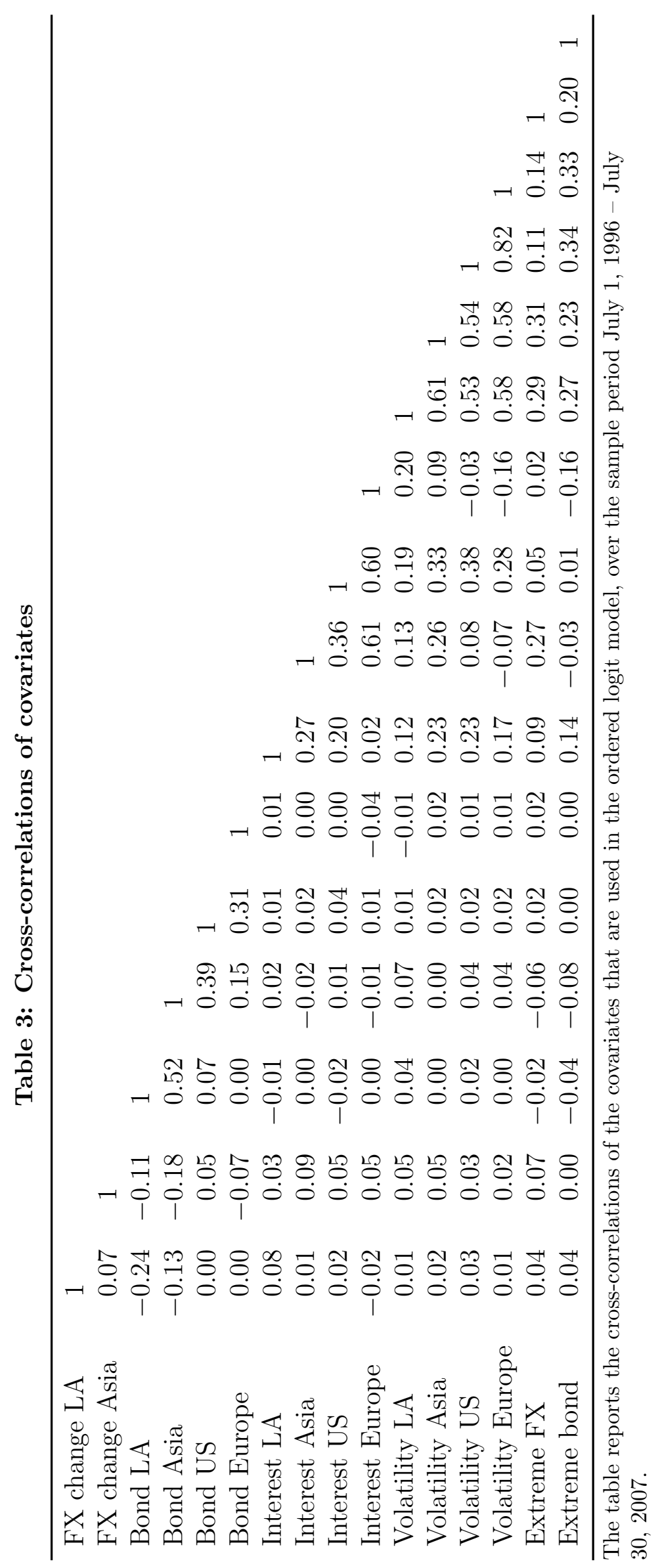


Table 4: Estimation results ordered logit model

\begin{tabular}{|c|c|c|c|c|}
\hline A: Coefficient estimates & Coefficient & St. error & $t$-stat. & $p$-value \\
\hline Currency change LA & -4.08 & 8.07 & -0.51 & 0.61 \\
\hline Currency change Asia & 6.55 & 7.68 & 0.85 & 0.39 \\
\hline Bond returns LA & -24.48 & 6.40 & -3.82 & 0.00 \\
\hline Bond returns Asia & -13.81 & 15.44 & -0.89 & 0.37 \\
\hline Bond returns US & 35.40 & 15.92 & 2.22 & 0.03 \\
\hline Bond Returns Europe & -10.33 & 6.80 & -1.52 & 0.13 \\
\hline Interest level LA & 0.00 & 0.00 & 0.44 & 0.66 \\
\hline Interest level Asia & 0.04 & 0.02 & 2.40 & 0.02 \\
\hline Interest level US & 0.05 & 0.08 & 0.61 & 0.54 \\
\hline Interest level Europe & 0.04 & 0.04 & 0.89 & 0.37 \\
\hline Volatility LA & 0.52 & 0.72 & 0.72 & 0.47 \\
\hline Volatility Asia & 1.88 & 0.85 & 2.20 & 0.03 \\
\hline Volatility US & 1.42 & 1.07 & 1.33 & 0.18 \\
\hline Volatility Europe & 2.44 & 1.24 & 1.97 & 0.05 \\
\hline Extreme FX count & 0.15 & 0.05 & 2.90 & 0.00 \\
\hline Extreme bond count & 0.03 & 0.03 & 0.85 & 0.39 \\
\hline Local crash dummy & 0.40 & 0.10 & 4.06 & 0.00 \\
\hline Regional crash dummy & 0.62 & 0.14 & 4.30 & 0.00 \\
\hline Global crash dummy & 1.21 & 0.21 & 5.83 & 0.00 \\
\hline$\alpha_{1}$ & 2.53 & 0.19 & & \\
\hline$\alpha_{2}$ & 3.90 & 0.19 & & \\
\hline$\alpha_{3}$ & 5.19 & 0.20 & & \\
\hline Log likelihood & -2613.26 & & & \\
\hline$R^{2}$ & 0.07 & & & \\
\hline
\end{tabular}

B: Joint significance tests on groups of variables

Log likelihood

d. f. $p$-value

\begin{tabular}{llll}
\hline Currencies & -2613.61 & 2 & 0.70 \\
Bonds & -2628.64 & 4 & 0.00 \\
Interest & -2623.23 & 4 & 0.00 \\
Volatilities & -2640.72 & 4 & 0.00 \\
Extreme events & -2618.41 & 2 & 0.01 \\
Past crashes & -2637.23 & 3 & 0.00 \\
\hline
\end{tabular}

The table reports estimation results for the ordered logistic regression model for the four different crash categories (no, local, regional, global), with covariates as shown in the table. The variables 'Local', 'Regional' and 'Global' are dummy variables taking the value one if this type of crash occurred on the previous day. The sample period runs from July 1, 1996 to July 30, 2007 (2839 observations). Panel B reports likelihood ratio tests on the joint significance of the coefficients for different groups of covariates. 


\section{Table 5: Marginal effects of prior crashes}

\begin{tabular}{ccccc}
\hline & $\mathrm{N}$ & $\mathrm{L}$ & $\mathrm{R}$ & $\mathrm{G}$ \\
\hline $\mathrm{N}$ & 0.65 & 0.21 & 0.09 & 0.05 \\
$\mathrm{~L}$ & 0.57 & 0.25 & 0.12 & 0.06 \\
$\mathrm{R}$ & 0.52 & 0.27 & 0.13 & 0.08 \\
$\mathrm{G}$ & 0.38 & 0.30 & 0.19 & 0.13 \\
\hline
\end{tabular}

The table contains the crash transition matrix as implied by the estimates of the ordered logit regression model in Table 4 . The $i j$-th element is the probability of observing the state in column $j$, given that on the previous day the state in row $i$ occurred. The row and column labels $\mathrm{N}, \mathrm{L}, \mathrm{R}$, and $\mathrm{G}$ correspond to no crash, local, regional and global crash, respectively. The reported probabilities are averages of the probabilities computed over all the possible values of the other covariates in the model. 
Table 6: Robustness checks

\begin{tabular}{|c|c|c|c|c|c|c|c|c|}
\hline & \multicolumn{2}{|c|}{ Check 1} & \multicolumn{2}{|c|}{ Check 2} & \multicolumn{2}{|c|}{ Check 3} & \multicolumn{2}{|c|}{ Check 4} \\
\hline & Coeff. & $p$-value & Coeff. & $p$-value & Coeff. & $p$-value & Coeff. & $p$-value \\
\hline Currency change LA & -4.70 & 0.58 & 0.28 & 0.98 & -2.27 & 0.79 & -5.13 & 0.55 \\
\hline Currency change Asia & -3.02 & 0.77 & 17.48 & 0.13 & 1.85 & 0.85 & 8.38 & 0.39 \\
\hline Bond returns LA & -15.22 & 0.01 & -14.22 & 0.03 & -28.89 & 0.00 & -25.40 & 0.00 \\
\hline Bond returns Asia & -22.02 & 0.15 & -21.44 & 0.18 & -16.62 & 0.26 & -15.81 & 0.29 \\
\hline Bond returns US & 34.46 & 0.03 & 51.37 & 0.00 & 40.97 & 0.01 & 40.87 & 0.01 \\
\hline Bond Returns Europe & -8.12 & 0.22 & -1.92 & 0.81 & -7.04 & 0.29 & -8.38 & 0.21 \\
\hline Interest level LA & 0.00 & 0.80 & 0.01 & 0.24 & 0.00 & 0.43 & 0.00 & 0.35 \\
\hline Interest level Asia & 0.06 & 0.00 & 0.03 & 0.12 & 0.04 & 0.03 & 0.04 & 0.02 \\
\hline Interest level US & 0.01 & 0.88 & 0.13 & 0.18 & 0.07 & 0.36 & 0.05 & 0.52 \\
\hline Interest level Europe & 0.01 & 0.74 & 0.03 & 0.56 & 0.03 & 0.50 & 0.03 & 0.38 \\
\hline Volatility LA & 0.16 & 0.81 & 0.73 & 0.33 & 0.95 & 0.16 & 0.68 & 0.31 \\
\hline Volatility Asia & -0.93 & 0.29 & 1.75 & 0.09 & 1.19 & 0.17 & 1.59 & 0.07 \\
\hline Volatility US & -0.19 & 0.86 & 0.65 & 0.60 & 1.48 & 0.16 & 1.50 & 0.15 \\
\hline Volatility Europe & 1.68 & 0.16 & 3.75 & 0.00 & 2.54 & 0.03 & 2.39 & 0.04 \\
\hline Extreme FX count & 0.16 & 0.00 & 0.26 & 0.00 & 0.15 & 0.00 & 0.15 & 0.00 \\
\hline Extreme bond count & 0.02 & 0.41 & 0.04 & 0.29 & 0.03 & 0.26 & 0.04 & 0.18 \\
\hline Local crash dummy & 0.54 & 0.00 & 0.42 & 0.00 & 0.40 & 0.00 & 0.40 & 0.00 \\
\hline Regional crash dummy & 0.71 & 0.00 & 0.33 & 0.08 & 0.74 & 0.00 & 0.70 & 0.00 \\
\hline Global crash dummy & 1.77 & 0.00 & 1.29 & 0.00 & 0.85 & 0.00 & 1.64 & 0.00 \\
\hline$\alpha_{1}$ & 1.50 & & 3.62 & & 2.49 & & 2.49 & \\
\hline$\alpha_{2}$ & 2.82 & & 4.88 & & 3.90 & & 3.85 & \\
\hline$\alpha_{3}$ & 4.21 & & 6.44 & & 5.30 & & 6.38 & \\
\hline Log likelihood & & -2677.35 & & -1868.91 & & -2664.57 & & -2555.44 \\
\hline$R^{2}$ & & 0.05 & & 0.09 & & 0.07 & & 0.08 \\
\hline
\end{tabular}

The table reports estimation results for different variations of the ordered logistic regression model for the four crash categories (no, local, regional, global), with covariates as shown in the table. The variables 'Local', 'Regional' and 'Global' are dummy variables taking the value one if this type of crash occurred on the previous day. The sample period runs from July 1, 1996 to July 30, 2007 (2839 observations). In check 1, crashes are defined using standardized returns. In check 2 , the 2.5 th quantile of the empirical distribution of the raw returns is used as the threshold to identify a crash. In check 3, a regional crash on day $t+1$ in Asia does not induce a global crash if the US or Europe encountered a crash on day $t$, while regional emerging market crashes are not said to occur when four or more individual emerging market countries in the region experience a crash. In check 4, global crashes only occur when three or more regions crash simultaneously. 
Table 7: Estimation results binomial logit model

\begin{tabular}{lrrrr}
\hline & Coeff. & St. error & $t$-stat. & $p$-value \\
\hline Currency change LA & 9.96 & 18.58 & 0.54 & 0.59 \\
Currency change Asia & -20.21 & 23.31 & -0.87 & 0.39 \\
Bond returns LA & -19.35 & 10.52 & -1.84 & 0.07 \\
Bond returns Asia & 12.89 & 26.49 & 0.49 & 0.63 \\
Bond returns US & 35.43 & 32.68 & 1.08 & 0.28 \\
Bond Returns Europe & -6.56 & 13.92 & -0.47 & 0.64 \\
Interest level LA & -0.02 & 0.01 & -1.15 & 0.25 \\
Interest level Asia & -0.02 & 0.05 & -0.34 & 0.73 \\
Interest level US & 0.60 & 0.18 & 3.29 & 0.00 \\
Interest level Europe & -0.06 & 0.09 & -0.62 & 0.54 \\
Volatility LA & 1.20 & 1.28 & 0.94 & 0.35 \\
Volatility Asia & 2.02 & 2.02 & 1.00 & 0.32 \\
Volatility US & -1.30 & 2.22 & -0.59 & 0.56 \\
Volatility Europe & 7.03 & 2.21 & 3.19 & 0.00 \\
Extreme FX count & 0.21 & 0.10 & 2.15 & 0.03 \\
Extreme bond count & 0.03 & 0.06 & 0.44 & 0.66 \\
Global crash dummy & 0.74 & 0.27 & 2.73 & 0.01 \\
& & & & \\
Constant & -6.40 & 0.51 & -12.42 & 0.00 \\
Log likelihood & -491.83 & & & \\
$R^{2}$ & 0.13 & & & \\
\hline
\end{tabular}

The table reports estimation results for the binomial logistic regression model for global crashes, with covariates as shown in the table. The variable 'Global' is a dummy variable taking the value one if a global crash occurred on the previous day. The sample period runs from July 1, 1996 to July 30, 2007 (2839 observations). 
Table 8: Estimation results from the general-to-specific model selection.

\begin{tabular}{lrrrr}
\hline A: Ordered logit model & & & & \\
& Coeff. & St. error & $t$-stat. & $p$-value \\
\hline Bond returns LA & -23.98 & 5.91 & -4.06 & 0.00 \\
Bond returns US & 43.93 & 19.70 & 2.23 & 0.03 \\
Interest level Latin America & -0.01 & 0.01 & -1.87 & 0.06 \\
Volatility Asia & 4.23 & 0.99 & 4.28 & 0.00 \\
Volatility Europe & 4.15 & 1.08 & 3.84 & 0.00 \\
Extreme FX count & 0.16 & 0.06 & 2.55 & 0.01 \\
Local crash dummy & 0.27 & 0.14 & 1.91 & 0.06 \\
Regional crash dummy & 0.68 & 0.18 & 3.76 & 0.00 \\
Global crash dummy & 0.92 & 0.28 & 3.27 & 0.00 \\
& & & & \\
$\alpha_{1}$ & 2.19 & 0.22 & & \\
$\alpha_{2}$ & 3.46 & 0.23 & & \\
$\alpha_{3}$ & 4.92 & 0.26 & & \\
Log likelihood & & & & \\
$R^{2}$ & -1290.05 & & & \\
\hline
\end{tabular}

B: Binomial model

\begin{tabular}{lrrrr} 
& \multicolumn{1}{c}{ Coeff. } & St. error & $t$-stat. & $p$-value \\
\hline Bond returns LA & -25.04 & 9.93 & -2.52 & 0.01 \\
Interest level US & 0.39 & 0.21 & 1.88 & 0.06 \\
Volatility Asia & 3.74 & 2.20 & 1.70 & 0.09 \\
Volatility Europe & 7.17 & 2.11 & 3.41 & 0.00 \\
Global & 0.72 & 0.43 & 1.67 & 0.09 \\
& & & & \\
constant & -6.76 & 0.92 & -7.36 & 0.00 \\
& & & & \\
Log likelihood & -229.69 & & & \\
$R^{2}$ & 0.13 & & & \\
\hline
\end{tabular}

The table reports the estimation results for the ordered and binomial logistic regressions, after the removal of insignificant coefficients. An iterative general-to-specific procedure is used where in each iteration the variable with the least significant coefficient estimate is removed, until all remaining coefficients are significant at the $10 \%$ level results. The remaining covariates in the final models are as shown in the table. The variables 'Local', 'Regional' and 'Global' are dummy variables taking the value one if this type of crash occurred on the previous day. The sample period runs from July 1, 1996 to December 31, 2001 (1421 observations). 
Table 9: Forecast performance evaluation

\begin{tabular}{|c|c|c|c|c|c|c|c|c|}
\hline \multirow[b]{2}{*}{$w$} & \multicolumn{4}{|c|}{ Ordered } & \multicolumn{4}{|c|}{ Binomial } \\
\hline & $H$ & $F$ & $K S$ & s.e. & $H$ & $F$ & $K S$ & s.e. \\
\hline 0.00 & 1.000 & 1.000 & 0.000 & 0.000 & 1.000 & 1.000 & 0.000 & 0.000 \\
\hline 0.01 & 1.000 & 0.999 & 0.001 & 0.001 & 1.000 & 0.727 & 0.273 & 0.012 \\
\hline 0.02 & 1.000 & 0.715 & 0.285 & 0.012 & 0.878 & 0.360 & 0.518 & 0.053 \\
\hline 0.03 & 0.927 & 0.381 & 0.546 & 0.043 & 0.732 & 0.197 & 0.535 & 0.070 \\
\hline 0.04 & 0.756 & 0.230 & 0.526 & 0.068 & 0.634 & 0.120 & 0.514 & 0.076 \\
\hline 0.05 & 0.683 & 0.151 & 0.532 & 0.073 & 0.561 & 0.097 & 0.464 & 0.078 \\
\hline 0.06 & 0.634 & 0.120 & 0.514 & 0.076 & 0.488 & 0.076 & 0.412 & 0.078 \\
\hline 0.07 & 0.585 & 0.092 & 0.493 & 0.077 & 0.439 & 0.062 & 0.377 & 0.078 \\
\hline 0.08 & 0.585 & 0.072 & 0.514 & 0.077 & 0.366 & 0.053 & 0.313 & 0.075 \\
\hline 0.09 & 0.512 & 0.064 & 0.448 & 0.078 & 0.293 & 0.044 & 0.248 & 0.071 \\
\hline 0.10 & 0.488 & 0.051 & 0.437 & 0.078 & 0.244 & 0.036 & 0.208 & 0.067 \\
\hline 0.11 & 0.366 & 0.041 & 0.325 & 0.075 & 0.244 & 0.031 & 0.213 & 0.067 \\
\hline 0.12 & 0.342 & 0.035 & 0.307 & 0.074 & 0.220 & 0.025 & 0.194 & 0.065 \\
\hline 0.13 & 0.268 & 0.029 & 0.239 & 0.069 & 0.220 & 0.020 & 0.199 & 0.065 \\
\hline 0.14 & 0.244 & 0.026 & 0.218 & 0.067 & 0.220 & 0.016 & 0.204 & 0.065 \\
\hline 0.15 & 0.244 & 0.024 & 0.220 & 0.067 & 0.220 & 0.014 & 0.206 & 0.065 \\
\hline 0.16 & 0.244 & 0.020 & 0.224 & 0.067 & 0.195 & 0.013 & 0.182 & 0.062 \\
\hline 0.17 & 0.220 & 0.019 & 0.201 & 0.065 & 0.195 & 0.013 & 0.182 & 0.062 \\
\hline 0.18 & 0.195 & 0.018 & 0.177 & 0.062 & 0.195 & 0.012 & 0.184 & 0.062 \\
\hline 0.19 & 0.171 & 0.017 & 0.154 & 0.059 & 0.195 & 0.011 & 0.184 & 0.062 \\
\hline 0.20 & 0.171 & 0.015 & 0.155 & 0.059 & 0.171 & 0.010 & 0.161 & 0.059 \\
\hline
\end{tabular}

The table reports the hit rate $(H)$, the false alarm rate $(F)$, and the Kuipers score $(K S=H-F)$ and its standard error, for probability forecasts of global crashes obtained from the ordered and the binomial logit models, for the period January 1, 2002 - July 30, 2007 (1417 observations). Probability forecasts exceeding the cut-off level $w$ are taken to be predictions of a global crash. 
Table 10: Regression results with crash dependent effects

\begin{tabular}{|c|c|c|c|c|}
\hline & Coefficient & St. error & $t$-statistic & $p$-value \\
\hline Currency change LA (N) & 0.08 & 14.78 & 0.01 & 1.00 \\
\hline Currency change LA (L) & 5.06 & 11.70 & 0.43 & 0.67 \\
\hline Currency change LA (R) & -6.48 & 28.25 & -0.23 & 0.82 \\
\hline Currency change LA (G) & -62.20 & 27.00 & -2.30 & 0.02 \\
\hline Local & 0.38 & 0.10 & 3.72 & 0.00 \\
\hline Regional & 0.60 & 0.15 & 4.05 & 0.00 \\
\hline Global & 1.37 & 0.20 & 6.77 & 0.00 \\
\hline Log likelihood & -2610.48 & & & \\
\hline$\chi(3)$ & 0.13 & & & \\
\hline Currency change Asia (N) & 8.21 & 14.14 & 0.58 & 0.56 \\
\hline Currency change Asia (L) & 26.37 & 20.22 & 1.30 & 0.19 \\
\hline Currency change Asia (R) & -5.93 & 19.13 & -0.31 & 0.76 \\
\hline Currency change Asia (G) & -44.27 & 46.35 & -0.96 & 0.34 \\
\hline Local & 0.38 & 0.10 & 3.74 & 0.00 \\
\hline Regional & 0.64 & 0.14 & 4.46 & 0.00 \\
\hline Global & 1.28 & 0.20 & 6.44 & 0.00 \\
\hline Log likelihood & -2611.92 & & & \\
\hline$\chi(3)$ & 0.44 & & & \\
\hline Bond returns LA (N) & -38.56 & 10.11 & -3.81 & 0.00 \\
\hline Bond returns LA (L) & -34.50 & 11.06 & -3.12 & 0.00 \\
\hline Bond returns LA (R) & -20.37 & 11.74 & -1.73 & 0.08 \\
\hline Bond returns LA (G) & 1.79 & 10.61 & 0.17 & 0.87 \\
\hline Local & 0.37 & 0.10 & 3.66 & 0.00 \\
\hline Regional & 0.58 & 0.14 & 4.10 & 0.00 \\
\hline Global & 1.37 & 0.20 & 6.90 & 0.00 \\
\hline Log likelihood & -2608.59 & & & \\
\hline$\chi^{2}(3)$ & 0.07 & & & \\
\hline Bond returns Asia $(\mathrm{N})$ & -54.95 & 23.96 & -2.29 & 0.02 \\
\hline Bond returns Asia (L) & -26.92 & 21.50 & -1.25 & 0.21 \\
\hline Bond returns Asia (R) & -7.49 & 29.42 & -0.25 & 0.80 \\
\hline Bond returns Asia (G) & 41.90 & 23.49 & 1.78 & 0.07 \\
\hline Local & 0.37 & 0.10 & 3.61 & 0.00 \\
\hline Regional & 0.57 & 0.14 & 4.03 & 0.00 \\
\hline Global & 1.23 & 0.19 & 6.48 & 0.00 \\
\hline Log likelihood & -2608.41 & & & \\
\hline$\chi^{2}(3)$ & 0.02 & & & \\
\hline Bond returns US (N) & 28.90 & 19.93 & 1.45 & 0.15 \\
\hline Bond returns US (L) & 53.31 & 29.58 & 1.80 & 0.07 \\
\hline Bond returns US (R) & 32.28 & 38.47 & 0.84 & 0.40 \\
\hline Bond returns US (G) & 33.10 & 57.41 & 0.58 & 0.56 \\
\hline Local & 0.40 & 0.10 & 4.04 & 0.00 \\
\hline Regional & 0.62 & 0.14 & 4.43 & 0.00 \\
\hline Global & 1.22 & 0.21 & 5.91 & 0.00 \\
\hline Log likelihood & -2613.00 & & & \\
\hline$\chi^{2}(3)$ & 0.91 & & & \\
\hline Bond returns Europe $(\mathrm{N})$ & -20.64 & 9.43 & -2.19 & 0.03 \\
\hline Bond returns Europe (L) & 16.12 & 13.06 & 1.23 & 0.22 \\
\hline Bond returns Europe (R) & -30.28 & 16.38 & -1.85 & 0.06 \\
\hline Bond returns Europe (G) & 4.00 & 19.12 & 0.21 & 0.83 \\
\hline Local & 0.40 & 0.10 & 3.98 & 0.00 \\
\hline Regional & 0.63 & 0.14 & 4.55 & 0.00 \\
\hline Global & 1.19 & 0.19 & 6.23 & 0.00 \\
\hline Log likelihood & -2609.50 & & & \\
\hline$\chi^{2}(3)$ & 0.06 & & & \\
\hline
\end{tabular}


Table 10: Regression results with crash dependent effects, continued

\begin{tabular}{|c|c|c|c|c|}
\hline & Coefficient & St. error & $t$-statistic & $p$-value \\
\hline Interest level LA (N) & 0.00 & 0.01 & 0.55 & 0.58 \\
\hline Interest level LA (L) & 0.01 & 0.01 & 0.97 & 0.33 \\
\hline Interest level LA (R) & -0.01 & 0.01 & -1.07 & 0.28 \\
\hline Interest level LA (G) & -0.03 & 0.03 & -1.05 & 0.30 \\
\hline Local & 0.33 & 0.16 & 2.07 & 0.04 \\
\hline Regional & 0.85 & 0.24 & 3.57 & 0.00 \\
\hline Global & 1.70 & 0.47 & 3.58 & 0.00 \\
\hline Log likelihood & -2611.53 & & & \\
\hline$\chi^{2}(3)$ & 0.32 & & & \\
\hline Interest level Asia (N) & 0.03 & 0.02 & 1.23 & 0.22 \\
\hline Interest level Asia (L) & 0.05 & 0.02 & 2.24 & 0.03 \\
\hline Interest level Asia (R) & 0.06 & 0.04 & 1.53 & 0.13 \\
\hline Interest level Asia (G) & -0.05 & 0.07 & -0.78 & 0.44 \\
\hline Local & 0.23 & 0.22 & 1.07 & 0.29 \\
\hline Regional & 0.42 & 0.30 & 1.40 & 0.16 \\
\hline Global & 1.69 & 0.44 & 3.81 & 0.00 \\
\hline Log likelihood & -2611.748 & & & \\
\hline$\chi^{2}(3)$ & 0.39 & & & \\
\hline Interest level US (N) & 0.05 & 0.09 & 0.53 & 0.60 \\
\hline Interest level US (L) & 0.13 & 0.12 & 1.03 & 0.30 \\
\hline Interest level US (R) & -0.14 & 0.17 & -0.79 & 0.43 \\
\hline Interest level US (G) & 0.13 & 0.23 & 0.55 & 0.58 \\
\hline Local & 0.14 & 0.42 & 0.35 & 0.73 \\
\hline Regional & 1.23 & 0.60 & 2.06 & 0.04 \\
\hline Global & 0.93 & 0.84 & 1.11 & 0.27 \\
\hline Log likelihood & -2612.28 & & & \\
\hline$\chi^{2}(3)$ & 0.58 & & & \\
\hline Interest level Europe $(\mathrm{N})$ & 0.03 & 0.04 & 0.77 & 0.44 \\
\hline Interest level Europe (L) & 0.04 & 0.06 & 0.72 & 0.47 \\
\hline Interest level Europe (R) & 0.07 & 0.07 & 0.91 & 0.36 \\
\hline Interest level Europe (G) & 0.00 & 0.09 & 0.00 & 1.00 \\
\hline Local & 0.37 & 0.27 & 1.39 & 0.16 \\
\hline Regional & 0.47 & 0.34 & 1.38 & 0.17 \\
\hline Global & 1.35 & 0.42 & 3.21 & 0.00 \\
\hline Log likelihood & -2613.04 & & & \\
\hline$\chi^{2}(3)$ & 0.93 & & & \\
\hline Volatility LA (N) & 1.04 & 0.85 & 1.22 & 0.22 \\
\hline Volatility LA (L) & 0.32 & 1.02 & 0.31 & 0.75 \\
\hline Volatility LA (R) & 1.26 & 1.17 & 1.08 & 0.28 \\
\hline Volatility LA (G) & -1.62 & 1.45 & -1.11 & 0.27 \\
\hline Local & 0.55 & 0.26 & 2.16 & 0.03 \\
\hline Regional & 0.53 & 0.34 & 1.55 & 0.12 \\
\hline Global & 1.93 & 0.46 & 4.15 & 0.00 \\
\hline Log likelihood & -2611.58 & & & \\
\hline$\chi^{2}(3)$ & 0.34 & & & \\
\hline Volatility Asia (N) & 2.74 & 1.05 & 2.60 & 0.01 \\
\hline Volatility Asia (L) & 1.86 & 1.32 & 1.41 & 0.16 \\
\hline Volatility Asia (R) & 1.26 & 1.82 & 0.69 & 0.49 \\
\hline Volatility Asia (G) & -6.99 & 3.10 & -2.26 & 0.02 \\
\hline Local & 0.54 & 0.28 & 1.94 & 0.05 \\
\hline Regional & 0.88 & 0.42 & 2.11 & 0.04 \\
\hline Global & 3.25 & 0.69 & 4.69 & 0.00 \\
\hline Log likelihood & -2608.58 & & & \\
\hline$\chi^{2}(3)$ & 0.02 & & & \\
\hline
\end{tabular}


Table 10: Regression results with crash dependent effects, continued

\begin{tabular}{|c|c|c|c|c|}
\hline & Coefficient & St. error & $t$-statistic & $p$-value \\
\hline Volatility US (N) & 2.42 & 1.21 & 1.99 & 0.05 \\
\hline Volatility US (L) & 0.84 & 1.54 & 0.55 & 0.58 \\
\hline Volatility US (R) & 0.10 & 1.80 & 0.06 & 0.95 \\
\hline Volatility US (G) & -0.23 & 2.29 & -0.10 & 0.92 \\
\hline Local & 0.66 & 0.27 & 2.44 & 0.01 \\
\hline Regional & 1.05 & 0.37 & 2.82 & 0.00 \\
\hline Global & 1.75 & 0.54 & 3.24 & 0.00 \\
\hline Log likelihood & -2611.83 & & & \\
\hline$\chi^{2}(3)$ & 0.41 & & & \\
\hline Volatility Europe (N) & 2.97 & 1.30 & 2.29 & 0.02 \\
\hline Volatility Europe (L) & 3.38 & 1.70 & 1.99 & 0.05 \\
\hline Volatility Europe (R) & 0.57 & 1.93 & 0.29 & 0.77 \\
\hline Volatility Europe (G) & 0.62 & 2.34 & 0.26 & 0.79 \\
\hline Local & 0.34 & 0.27 & 1.23 & 0.22 \\
\hline Regional & 1.06 & 0.37 & 2.86 & 0.00 \\
\hline Global & 1.71 & 0.54 & 3.15 & 0.00 \\
\hline Log likelihood & -2611.88 & & & \\
\hline$\chi^{2}(3)$ & 0.43 & & & \\
\hline Extreme FX (N) & 0.13 & 0.08 & 1.70 & 0.09 \\
\hline Extreme FX (L) & 0.19 & 0.09 & 2.21 & 0.03 \\
\hline Extreme FX (R) & 0.17 & 0.10 & 1.72 & 0.09 \\
\hline Extreme FX (G) & 0.09 & 0.14 & 0.67 & 0.50 \\
\hline Local & 0.37 & 0.12 & 3.10 & 0.00 \\
\hline Regional & 0.59 & 0.16 & 3.58 & 0.00 \\
\hline Global & 1.26 & 0.23 & 5.51 & 0.00 \\
\hline Log likelihood & -2613.00 & & & \\
\hline$\chi^{2}(3)$ & 0.91 & & & \\
\hline Extreme bond (N) & 0.08 & 0.04 & 1.81 & 0.07 \\
\hline Extreme bond (L) & 0.02 & 0.05 & 0.46 & 0.64 \\
\hline Extreme bond (R) & 0.00 & 0.07 & -0.03 & 0.97 \\
\hline Extreme bond $(\mathrm{G})$ & -0.15 & 0.09 & -1.79 & 0.07 \\
\hline Local & 0.44 & 0.12 & 3.71 & 0.00 \\
\hline Regional & 0.69 & 0.17 & 3.94 & 0.00 \\
\hline Global & 1.53 & 0.23 & 6.59 & 0.00 \\
\hline Log likelihood & -2610.18 & & & \\
\hline$\chi^{2}(3)$ & 0.10 & & & \\
\hline
\end{tabular}

The table reports estimation results for the ordered logistic regression model for the four different crash categories (no, local, regional, global), with covariates as shown in Table 4., but in each regression one original variable is conditioned on the occurrence of a crash on the previous day. Thus, in each case we multiply the variable under consideration with the past crash dummies (including a no crash dummy), which gives rise to four variables. For convenience we only report coefficient estimates for the crash dummies and for the crash conditioned variable, where the labels $(\mathrm{N}),(\mathrm{L}),(\mathrm{R})$ and $(\mathrm{G})$ refer to no crash, and local, regional and global crash, respectively. The $\chi^{2}(3)$-statistic tests whether conditioning a variable significantly improves the model. The sample period runs from July 1, 1996 to July 30, 2007 (2839 observations). 


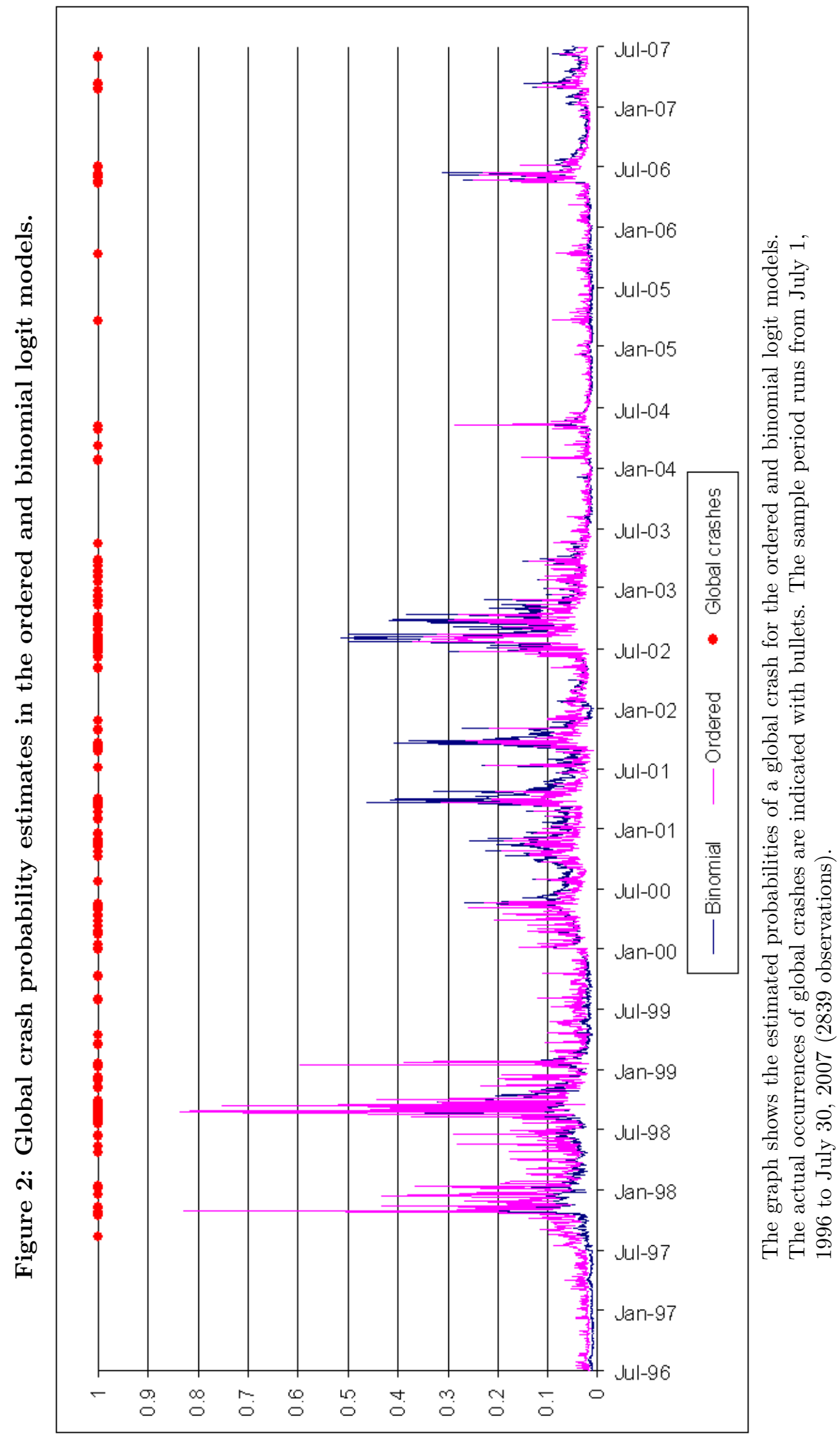




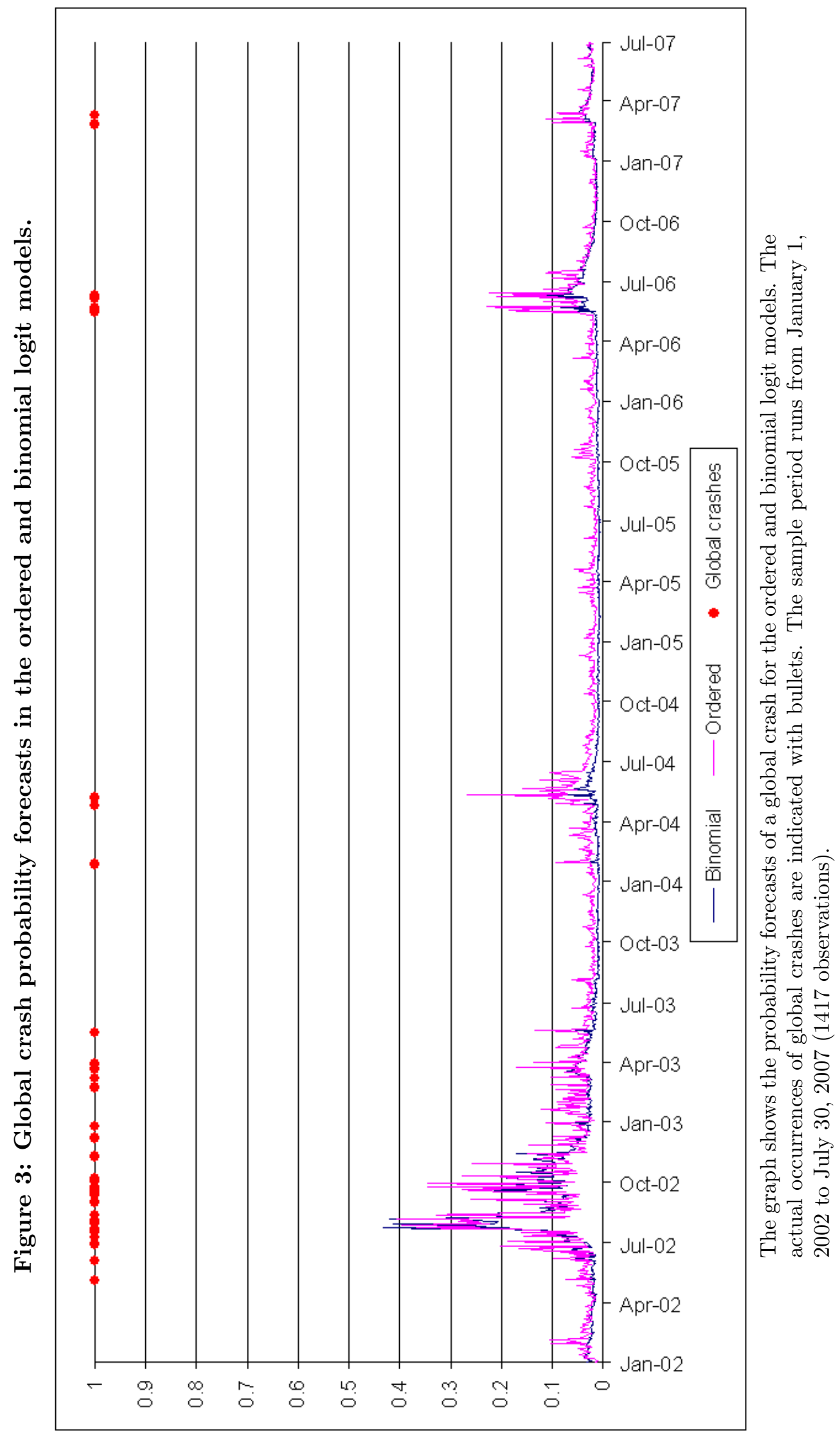




\section{Publications in the Report Series Research* in Management}

\section{ERIM Research Program: "Finance and Accounting"}

\section{8}

The Inefficient Use of Macroeconomic Information in Analysts' Earnings Forecasts in Emerging Markets Gerben de Zwart and Dick van Dijk

ERS-2008-007-F\&A

http://hdl.handle.net/1765/11556

Sole versus Shared Responsibility: Fraud Consultation and Auditor Judgment

Anna Gold-Nöteberg, W. Robert Knechel and Philip Wallage

ERS-2008-010-F\&A

http://hdl.handle.net/1765/11687

Corporate Governance and the Value of Excess Cash Holdings of Large European Firms

Marc B.J. Schauten, Dick van Dijk and Jan-Paul van der Waal

ERS-2008-027-F\&A

http://hdl.handle.net/1765/12465

A Conceptual Model of Investor Behavior Milan Lovric, Uzay Kaymak and Jaap Spronk

ERS-2008-030-F\&A

http://hdl.handle.net/1765/12468

Impact of Japanese Mergers on Shareholder Wealth: An Analysis of Bidder and Target Companies

Vikas Mehrotra, Dimitri van Schaik, Jaap Spronk and Onno W. Steenbeek

ERS-2008-032-F\&A

http://hdl.handle.net/1765/12597

Global Tactical Cross-Asset Allocation: Applying Value and Momentum Across Asset Classes

David Blitz and Pim van Vliet

ERS-2008-033-F\&A

http://hdl.handle.net/1765/12598

Contagion as Domino Effect in Global Stock Markets

Thijs Markwat, Erik Kole, and Dick van Dijk

ERS-2008-071-F\&A

http://hdl.handle.net/1765/13835

* A complete overview of the ERIM Report Series Research in Management: https://ep.eur.nl/handle/1765/1

ERIM Research Programs:

LIS Business Processes, Logistics and Information Systems

ORG Organizing for Performance

MKT Marketing

F\&A Finance and Accounting

STR Strategy and Entrepreneurship 